NBER WORKING PAPER SERIES

\title{
EQUILIBRIUM EFFECTS OF PAY TRANSPARENCY
}

\author{
Zoe B. Cullen \\ Bobak Pakzad-Hurson \\ Working Paper 28903 \\ http://www.nber.org/papers/w28903
NATIONAL BUREAU OF ECONOMIC RESEARCH
1050 Massachusetts Avenue
Cambridge, MA 02138
June 2021, Revised August 2022

We are extremely grateful to Aviv Nevo and five anonymous referees. One referee in particular shifted the direction of this paper, and we are extremely appreciative of their contribution. We are very grateful for guidance from Ran Abramitzky, Susan Athey, Nick Bloom, Matt Jackson, Fuhito Kojima, Ed Lazear, Luigi Pistaferri, Al Roth, and Gavin Wright. We also thank Mohammad Akbarpour, Lint Barrage, Jose Maria Barrero, Doug Bernheim, Ben Brooks, Eric Budish, Gabriel Carrol, Arun Chandrasekhar, Kalyan Chatterjee, Isa Chaves, Ken Chay, Bo Cowgill, Piotr Dworczak, Jack Fanning, Chiara Farronato, Laura Gee, Matt Gentzkow, Avi Goldfarb, Bob Hall, Gregor Jarosch, Scott Kominers, Maciej Kotowski, Vijay Krishna, Jon Levin, Shengwu Li, Erik Madsen, Davide Malacrino, Alejandro Martinez, Paul Milgrom, Muriel Niederle, Ricardo Perez-Truglia, Kareen Rozen, Ilya Segal, Isaac Sorkin, Jesse Shapiro, Chris Stanton, Bryce Millet Steinberg, Takuo Sugaya, Neil Thakral, Catherine Tucker, Christopher Snyder, Emmanuel Vespa, and Alistair Wilson and seminar attendees at Stanford, UCLA Anderson, NYU Stern, HBS, Dartmouth, Brown, USC, UCSD, UCSB, Penn State, Michigan SI, Berkeley, Kellogg, Columbia, Michigan, CMU, BU, AEA, SIEPR, EC'19, SOLE, and NBER SI (Digitization and Personnel) for helpful comments and suggestions. We are indebted to Chloe Lee, and especially Dylan Balla-Elliott and Diego Gentile for excellent research assistance. This research was supported by the Center for Comparative Studies in Race and Ethnicity and the B.F. Haley and E.S. Shaw Fellowship through SIEPR. The views expressed herein are those of the authors and do not necessarily reflect the views of the National Bureau of Economic Research.

NBER working papers are circulated for discussion and comment purposes. They have not been peer-reviewed or been subject to the review by the NBER Board of Directors that accompanies official NBER publications.

(C) 2021 by Zoe B. Cullen and Bobak Pakzad-Hurson. All rights reserved. Short sections of text, not to exceed two paragraphs, may be quoted without explicit permission provided that full credit, including $\odot$ notice, is given to the source. 
Equilibrium Effects of Pay Transparency

Zoe B. Cullen and Bobak Pakzad-Hurson

NBER Working Paper No. 28903

June 2021, Revised August 2022

JEL No. C78,D82,D83,J31,M52

\begin{abstract}
$\underline{\text { ABSTRACT }}$
The public discourse around pay transparency has focused on the direct effect: how workers seek to rectify pay inequities through renegotiation. The question of how wage-setting and employment practices of the firm respond has received less attention. To study these equilibrium outcomes, we test our model of bargaining under incomplete information with an analysis of pay transparency mandates in the context of the U.S. private sector. Our model predicts that transparency reduces the individual bargaining power of workers, leading to lower average wages. A key insight is that employers credibly refuse to pay high wages to any one worker to avoid costly renegotiations with others under transparency. In situations where workers do not have individual bargaining power, such as under a collective bargaining agreement or in markets with posted wages, greater transparency has a muted impact on average wages. We test these predictions by evaluating the adoption of U.S. state legislation protecting the right of workers to inquire about the salaries of their coworkers. Consistent with our prediction, the laws lead wages to decline by approximately $2 \%$ overall, but effects are muted when workers have low individual bargaining power. Our model provides a unified framework to analyze a wide range of transparency policies, and reconciles effects of transparency mandates documented in a variety of countries and contexts.
\end{abstract}

Zoe B. Cullen

Rock Center 210

Harvard Business School

60 N. Harvard

Boston, MA 02163

and NBER

zcullen@hbs.edu

Bobak Pakzad-Hurson

Brown University

64 Waterman Street

Providence, RI 02912

bph@brown.edu 


\section{INTRODUCTION}

Most pay transparency initiatives are based on the narrative that transparency gives workers more bargaining power. Pay transparency laws aim to increase workers' knowledge of the pay of their peers to ensure "victims of pay discrimination can effectively challenge unequal pay," equipping them for successful negotiations by revealing their employer's willingness to pay for labor (Phillips, 2009). But the use of salary disclosure to remedy unequal pay for equal work is only half of the story; when salary transparency is anticipated by the employer and employees, optimal wage-setting, bargaining, and employment practices also adjust. Despite a lack of evidence on the indirect effects of pay transparency, 22 U.S. states and $10 \mathrm{EU}$ countries have passed laws to increase pay transparency. ${ }^{1}$

Our paper studies how the indirect effects of pay transparency policies on wage negotiations can lead to an unintended equilibrium outcome. We combine a dynamic wage-bargaining model with an event-study analysis of the enactment of U.S. state level pay transparency laws. Our theory predicts the indirect effects brought about by employer adjustments in wage-setting and hiring policies decreases workers' de facto bargaining power, and consequentially lowers average wages. Our empirical analysis corroborates this indirect channel: average wages among private sector employees fall following pay transparency mandates in states that increase pay transparency.

To introduce the mechanisms we study in this paper, we present two scenarios. First, suppose a worker learns that a colleague with the same job is earning significantly more than she is. She reasons that her employer must be willing to pay a higher wage for the work she is doing, and will therefore seek to renegotiate her wage. These renegotiations lead to higher wages, the first part of the story.

To see the second part of the story, consider wage negotiations when there is full pay transparency. A worker not only knows the wages of her peers, but also recognizes that her wage will be visible to her coworkers. Suppose she demands higher pay than her peers receive. The employer can credibly reject this demand, saying, "If I give you a higher salary, I'll have to give everyone else a raise too, and I just can't afford that." Under pay secrecy, the worker might have been skeptical of such a claim and bargained more aggressively, but due to transparency, the worker grasps the (true and costly) ramifications of asking for more than the current maximum wage earned by others. Therefore, full transparency leads to an unintended side effect: if workers all get the same wage and cannot negotiate this wage upward, then the firm gets the power to set the wage. To maximize its profit, the firm acts like a monopsonist and sets a relatively low wage. Thus transparency increases the de facto bargaining power of the employer, becoming the enforcement mechanism for a low wage.

In this way, transparency resembles best-price guarantees which rebate existing customers if

\footnotetext{
${ }^{1}$ The policies in the U.S. range from punishments for employers that prevent employees from discussing salaries (Siniscalco et al., 2017) to requirements that employers inform prospective employees of the range of salaries currently paid to workers (Pender, 2017). EU policies range from full disclosure internally (large German firms) to publication of salary statistics such as the mean, median, and gap between men and women, as in the case of the U.K. and Denmark (International Labour Organization, 2018; Veldman, 2017).
} 
prices fall in the future. These agreements are theoretically shown to increase the commitment power of sellers, allowing them to maintain higher prices (Butz, 1990; Cooper and Fries, 1991), and empirical evidence supports these findings (Scott Morton, 1997a,b). However, a point of departure when analyzing the equilibrium effects of pay transparency is that the value of the good (labor) is private information.

We study a dynamic model of wage bargaining with two-sided incomplete information. We model pay transparency as the probability of observing peer wages. Mechanically, transparency provides information that workers can exploit in renegotiations. In some cases, it can also increase the likelihood a wage renegotiation occurs at all. ${ }^{2}$ Both of these alter the de facto bargaining power through two equilibrium effects: a demand effect and a supply effect. As transparency rises, the firm's maximum willingness to pay for labor falls because information about one worker's pay raise spreads more quickly to others, who use that information to renegotiate (demand effect). At the same time, workers make lower initial wage offers to increase their chances of getting hired (supply effect). Because workers expect to quickly learn the wages of others and renegotiate with higher transparency, they are less concerned with securing a high initial wage.

Dynamic games with incomplete information frequently contain analogues of one of these effects, but not, to our knowledge, both. In the well-known chain store game, Kreps and Wilson (1982) and Milgrom and Roberts (1982) show that costly, predatory behavior against early competitors may be optimal in order to create a reputation favorable for later negotiations (demand effect). Kuhn and $\mathrm{Gu}(1998,1999)$ show that unions optimally delay making contract offers to employers so that they can freeride on information gathered from the negotiations of others (supply effect). ${ }^{3}$ Our setting includes both of these supply and demand effects, which cause simultaneous adjustments of bargaining strategies by workers and the firm in response to changes in transparency. We prove several novel equilibrium results.

We show that increasing transparency has the same equilibrium effect as decreasing worker bargaining power, and results in lower wages. Formally, we show a mapping between the equilibria of our dynamic game and that of static double auctions studied by Chatterjee and Samuelson (1983). ${ }^{4}$ The equilibria of our game under high transparency and high worker bargaining power are identical to the equilibria with lower transparency and lower worker bargaining power. Full transparency grants the firm full de facto bargaining power when renegotiations are common, as

${ }^{2}$ We do not explicitly model the mechanism by which observing peer wages enables a worker to "bring the firm to the bargaining table." Empirical evidence from Biasi and Sarsons (2021) and Cullen and Pakzad-Hurson (2022) supports that the observation of peer wages increases the rate of rengotiation; Biasi and Sarsons (2021) find that "knowing the pay of colleagues is associated with a 5.7 percentage point (24 percent) higher chance of having negotiated after the start of the current contract" (page 176).

${ }^{3} \mathrm{Gu}$ and Kuhn (1998) show that an analogue of the demand effect may be present in this setting, although they do not consider both effects simultaneously.

${ }^{4}$ Double auctions serve as useful empirical approximations to real-world bargaining in settings with private information (Larsen, 2021; Larsen and Zhang, 2018). 
the firm commits to, and workers observe and adhere to, a maximum wage. ${ }^{5}$ By Williams (1987), this maximizes expected firm profits and minimizes expected worker surplus and wages.

In environments where workers have low bargaining power to begin with, the effects of higher transparency on wages are muted. The reason is that workers, at baseline, are less able to exploit differences in their outside options to secure heterogeneous wages, and as a result there is less scope for upward wage renegotiation. In markets where workers have no individual bargaining power, such as markets with posted wages or markets where wages are set by a collective or union, transparency will not affect wages in equilibrium.

Pay transparency has a non-monotonic effect on employment because employment is maximized when bargaining power is shared between workers and the firm. When bargaining power is highly skewed, either workers act like monopolists, making high wage demands that are often rejected; or the firm acts like a monopsonist, committing to low wages that deter high-outside-option workers from considering work at the firm. Granting either the firm or workers all of the bargaining power minimizes expected employment. ${ }^{6}$

We study these equilibrium effects empirically in an event study framework. Since 2004, 18 U.S. states and the District of Columbia have enacted policies aimed at facilitating communication about pay between coworkers. The policies impose punishments for employers that retaliate against workers who disclose their wages or inquire about the wages of coworkers. We refer to these as "Right of Workers To Talk" (ROWTT) policies. Nationally representative surveys in 2010 and 2018, conducted by Hegewisch et al. (2011) and Sun et al. (2021), reveal that the share of private-sector employees prohibited from discussing pay with co-workers fell from $33.2 \%$ to $9.9 \%$ in states that enact ROWTT legislation, while the share in all other states fell by a small fraction in comparison.

We examine the effect of ROWTT policies on private-sector workers using data from the American Community Survey (ACS). Our window of analysis runs from the inception of the ACS in 2000 to 2016, when related federal policies rolled out across all states. Our identifying assumption is that the timing of when states enact ROWTT is uncorrelated with wage and employment dynamics. We empirically verify this assumption by examining how labor market outcomes evolve in each state leading up to the enactment of ROWTT.

Corroborating our main theoretical finding, wages fall as pay transparency rises. In the year following the enactment of the ROWTT, wages fall by $2.2 \%$ and are statistically different from zero,

\footnotetext{
${ }^{5}$ Because of this equilibrium equivalence between full transparency and posted wages, our model has the advantage of being able to reproduce the a range of findings in prior work. Michelacci and Suarez (2006) show that bargaining leads to more dispersed wages than posted wages (our Theorem 4); Ellingsen and Rosén (2003) find wage posting is more effective than bargaining when reservation wages are low (an implication of our Theorem 3); Brenzel et al. (2014) suggest that bargaining may lead to higher average worker wages than wage posting (our Theorem 2).

${ }^{6}$ The potential positive effect of pay transparency on employment is perhaps surprising given results of other models of bargaining with private information (Bergemann and Hörner, 2018; Brancaccio et al., 2020; Hörner and Vieille, 2009; Kaya and Liu, 2015). All find that transparency decreases the number of (or prevents) transactions. However, in models without private information, labor market interventions may lead to non-monotonic employment responses (see, eg. Loertscher and Muir, 2021b).
} 
and decline $2.7 \%$ by the third year after the policy. Our conclusions hold across many specifications, including allowing for heterogeneous treatment effects across cohorts and re-weighting observations to hold the composition of the workforce fixed within gender-by-education cells.

Wage declines can result from two channels in our model: a direct reduction in wage rates and, under some circumstances, reduced employment of high outside option workers who demand higher wages. Both are a consequence of lower worker bargaining power under higher pay transparency. Empirically, we find support for a direct reduction in wage rates. Private sector employment levels rise on average $0.5 \%$. We bound the impact of workforce composition changes on wage declines by using the upper end of the $95^{\text {th }}$ percent confidence interval as our measure of labor entry, and assuming all those joining the the workforce earn zero wages. We estimate less than one third of the reduction in wages stems from composition changes. Re-weighting to fix the composition of the workforce within education-by-gender cells also reveals limited impact of entry and exit of workers on the wage decline.

To investigate the interaction between individual bargaining power and transparency policies, we separately examine labor markets where we expect low versus high individual worker bargaining power. In our model, the lowest level of individual bargaining power occurs when workers face take-it-or-leave-it (TIOLI) wage offers. Hall and Krueger (2012) find that the two leading predictors of facing a TIOLI wage offer, as opposed to wage bargaining, are low education (those with a 4-year college degree are 1.5 times as likely to bargain as those without), and union membership (non-union members are 2.3 times as likely to bargain as unionized workers). In line with our theoretical predictions, workers with limited individual bargaining power-workers without 4-year college degrees and those in occupations with above-median unionization-experience negligible wage declines following ROWTT. We rule out wage declines larger than $2.7 \%$ and $1.7 \%$ for these groups, respectively. By contrast, workers with a 4-year college degree experience a $3.2 \%$ wage decline on average and those in occupations with below-median unionization experience a $2.5 \%$ wage decline on average. We caution that there exist differences between these groups that we cannot control for in this analysis. However, as we detail below, these estimates fall in line with similar figures across labor markets in five countries.

We extend our theoretical framework to encompass pay transparency policies that have been evaluated in other settings. We show that other policies, including the publication of average pay gaps between groups, also shift equilibrium de facto bargaining power away from workers as in our baseline model. This allows us to investigate our predictions across markets with distinct institutions.

Our framework reconciles heterogeneous impacts of pay transparency policies documented in different labor markets and geographies. A comprehensive review of studies that evaluate the effect of pay transparency on the wages of all employed workers yields nine studies, spanning five countries (Baker et al., 2021; Bennedsen et al., 2019; Blundell, 2021; Böheim and Gust, 2021; 
Duchini et al., 2020; Gulyas et al., 2020; Mas, 2017; Obloj and Zenger, 2020). These studies are broadly focused on wage compression, but as a secondary outcome, some studies report a significant decrease in wages, while others find a tight null effect on wages. We contextualize these findings by proxying the degree of individual bargaining power workers have in each study based on the share of workers covered by a union or collective bargaining agreements. We find that in markets with high individual bargaining power (low unionization rates), pay transparency mandates lower average wages around $2 \%$, as we find in the context of the U.S. private sector. In markets with low individual bargaining power (high unionization rates), pay transparency mandates have little to no effect on wages. We conduct a mixed-effects meta-regression analysis and find that a 10 pp decrease in share of labor market unionization is associated with $0.18 \mathrm{pp}$ lower wages following the transparency mandate. The differential wage effects persist for at least four years.

While we are unable to test model predictions that hold within firm using the American Community Survey, several studies in our meta-analysis overcome this limitation with matched firm-worker observation. An important prediction of our model is that wages will be more equal within a firm as low-outside option workers benefit relatively more from transparency. Empirical support for compression within firm can be found in the studies included in our meta-analysis. Six of nine studies find that wages for men decline more than wages for women when evaluating the effect of transparency mandates on within firm wages, consistent with our model's predictions of wage compression when men's outside options are higher than women's.

Our finding that pay transparency lowers worker bargaining power raises the question of why we do not observe more firms voluntarily selecting high levels of transparency. Indeed, well-cited studies find that the majority of firms attempt to limit pay transparency (Hegewisch et al., 2011; McCarthy, 2018). Theoretically we find that transparency mandates lower worker bargaining power, and that these mandates may also serve a critical function in allowing the firm to contract on the level of transparency. In the absence of a mandate, a firm would prefer to shirk on its promise of transparency. Consider a firm that promises a worker to post wages on a company message board, to be updated whenever wages adjust, in order to reach a favorable initial wage agreement. After the negotiation, the firm would have a profitable deviation to simply neglect updating the message board, or worse, systematically under-report wages. In equilibrium, our model predicts that when the firm cannot contract on the level of transparency, it will select full secrecy regardless of the profit-maximizing exogenous level of transparency. This points to an important role for transparency legislation, and in particular, policies that promote credible information, such as protections for co-workers to circulate salary information.

The remainder of the paper is organized as follows. Section II lays out our model and presents our main theoretical findings. Section III.A describes our event-study analysis of U.S. state ROWTT laws. Section III.B presents our meta analysis. Section IV concludes. Omitted proofs, additional empirical results, and extensions are contained in the Appendix. 


\section{MODEL}

\section{II.A. Setup}

There are two time periods $t \in\{1,2\}$. There is a single firm, and a unit-measure set of workers I. Each worker $i \in I$ has a private outside option $\theta_{i} \stackrel{i i d}{\sim} G[0,1]$, which is the payoff $i$ receives if unemployed. ${ }^{7}$ The firm has a constant-returns-to-scale production function. We assume for now that productivity of labor is common across all workers: it receives (infinitesimal) payoff $v \sim F[0,1]$ for each hired worker, where $v$ is private information of the firm. (We discuss the case in which workers are heterogeneously productive in Section D.1.) We assume that $F$ and $G$ are twice continuously differentiable with densities $f$ and $g$, respectively, where $f(x)>0$ for all $x \in(0,1]$ and $g(y)>0$ for all $y \in[0,1)$. We also assume agents have strictly increasing virtual reservation values, i.e. $\theta+\frac{G(\theta)}{g(\theta)}$ is strictly increasing in $\theta$ and $v-\frac{1-F(v)}{f(v)}$ is strictly increasing in $v$.

Before any workers arrive, the firm commits to a persistent maximum wage $\bar{w}(v) \in[0,1]$; the firm does not individually tailor wage offers to workers, as is empirically documented in Di Addario et al. (2022). ${ }^{8} \bar{w}$ is not immediately observed by workers. An initial round of bargaining takes place at $t=1$. Each worker $i$ commits to a walk-away wage at $t=1$, which we refer to as her initial offer, $\underline{w}_{i, 1}\left(\theta_{i}\right) \in[0,1]$. As in a double auction (Chatterjee and Samuelson, 1983), $i$ is employed if and only if $\underline{w}_{i, 1} \leq \bar{w}$. If hired, $i$ 's initial wage $w_{i, 1}$ is a random variable that equals $\underline{w}_{i, 1}$ with probability $1-k$ and equals $\bar{w}$ with probability $k$ (independently across workers), where $k \in[0,1]$ is the known "bargaining weight" of the firm. Let $I_{1}$ represent the set of all workers hired at this stage.

We model transparency as the random arrival of information about current wages. At time $t=2$ each matched worker $i \in I_{1}$ observes the set of negotiated wages, $\left\{w_{i, 1}\right\}_{i \in I_{1}}$, with independent probability $\Lambda \in[0,1]$. Therefore, $\Lambda$ defines the level of pay transparency.

Each employed worker $i \in I_{1}$ who observes the wages of her peers renegotiates with the firm with probability $P \in[0,1]$ by making a new offer $\underline{w}_{i, 2}$. Let $I_{2} \subset I_{1}$ be the set of initially employed workers who remain employed, either by not renegotiating with the firm or by making second-round offers weakly less than $\bar{w}$ (i.e. $\underline{w}_{i, 2} \leq \bar{w}$ ). For each $i \in I_{2}$, the final wage $w_{i}$ is determined as follows: if $i$ did not renegotiate her wage, $w_{i}=w_{i, 1}$. If $i$ did renegotiate her wage, $w_{i}$ equals $\underline{w}_{i, 2}$ with probability $1-k$ and $\bar{w}$ with probability $k$, independently across workers.

All agents are risk neutral and wish to maximize their payoff, where a worker's payoff is $w_{i}$ for all employed workers $i \in I_{2}$ and $\theta_{i}$ otherwise, and the firm's (infinitesimal) payoff from each employed worker $i \in I_{2}$ is $v-w_{i}$, and 0 otherwise.

\footnotetext{
${ }^{7}$ There is a known measurability issue with the assumption of a continuum of i.i.d. random variables (Judd, 1985). A solution is to assume that worker outside options are drawn "almost" i.i.d. in the sense of Sun (2006). This solves the measureability issue and has the intuitive and intended property that the distribution of realized outside options is given by the same function $G(\cdot)$.

${ }^{8}$ We discuss the case in which the firm can set different maximum wages to ex-ante heterogeneous workers in Appendix Section D.1.
} 


\section{II.B. Equilibrium existence}

We investigate pure strategy perfect Bayesian equilibria (PBE) of the game which satisfy the following regularity conditions:

A1 $0 \leq \bar{w} \leq v$ for all $v$. If $v \leq \underline{w}_{i, 1}$ for every worker $i$ according to equilibrium strategies then $\bar{w}=v$.

A2 $\theta_{i} \leq \underline{w}_{i, 1} \leq 1$ for all $i$. If there is no $v$ such that $\theta_{i} \leq \bar{w}$ according equilibrium strategies then $\underline{w}_{i, 1}=\theta_{i}$.

A3 $\bar{w}$ and $\underline{w}_{i, 1}$ are strictly increasing functions of $v$ and $\theta_{i}$, respectively. Moreover, $\bar{w}$ is continuously differentiable for $v \in\left(\underline{w}_{i, 1}(0), 1\right)$ and $\underline{w}_{i, 1}$ is continuously differentiable for $\theta \in(0, \bar{w}(1))$.

A1 and A2 restrict actions of agents who never match in equilibrium, because either the firm's value for labor is too low or the worker's outside option is too high. These assumptions rule out pathological equilibria in which, for example, $\bar{w}=0$ for all $v$ and all workers offer $\underline{w}_{i, 1}=1$. A3 assists in tractability. It also removes equilibria in which workers and the firm pool on a predetermined wage from consideration. ${ }^{9}$ There always exists an equilibrium of the game satisfying A1-3.

Proposition 1. The set of equilibria is non-empty. In any equilibrium, each worker receives $\bar{w}$ upon renegotiating.

\section{II.C. Effect of transparency on bargaining power}

In this section, we show that an increase in transparency lowers de facto worker bargaining power in any equilibrium. We describe this connection here, which also provides a sketch for the proof of Proposition 1. In Section II.D we describe testable predictions of this equivalence relationship between bargaining power and transparency on labor market outcomes following an increase in transparency.

In equilibrium, each worker receives a final wage equal to $\bar{w}$ upon renegotiating; by $\mathbf{A} \mathbf{3}$ workers trace out the set $[a, 1], a>0$ with their initial wage offers. Therefore, there is some worker $j$ who receives initial wage $w_{j, 1}=\bar{w}$ for any $k \in[0,1]$ (assuming the firm hires a positive measure of workers, i.e. $\bar{w} \geq a$ ), and any worker $i$ who observes peer wages and renegotiates will offer and receive $\underline{w}_{i, 2}=w_{j, 1}=\bar{w}$.

Therefore, any employed worker $i$ who offers $\underline{w}_{i, 1}<\bar{w}$ will receive final wage $w_{i}=\bar{w}$ if either: $w_{i, 1}=\bar{w}$ (which occurs with probability $k$ ), or if she observes peer wages and renegotiates (which occurs with probability $\Lambda P$ ). With the complementary probability, $i$ receives final wage $w_{i}=\underline{w}_{i, 1}$.

${ }^{9}$ Leininger et al. (1989) suggest similarities between the set of continuous equilibria and a set of discontinuous equilibria in static double auctions, and so we do not believe this to be a conceptually limiting constraint. We discuss the connection of our game to static double auctions below. 
Letting $\bar{F}(x)=P(\bar{w} \leq x)$, and $\bar{G}(x)=P\left(\underline{w}_{i, 1} \leq x\right)$ for $x \in[0,1]$ (with densities $\bar{f}(\cdot)$ and $\bar{g}(\cdot)$, respectively) we show in Appendix Section $\mathrm{C}$ that each worker $i$ and the firm respectively solve

$$
\begin{gathered}
\underline{w}_{i, 1}=\underset{w}{\operatorname{argmax}} \int_{w}^{1}\left((1-\Omega) w+\Omega x-\theta_{i}\right) \bar{f}(x) d x \\
\bar{w}=\underset{w}{\operatorname{argmax}} \int_{0}^{w}(v-(1-\Omega) y-\Omega w) \bar{g}(y) d y
\end{gathered}
$$

where

$$
\Omega=k+(1-k) \Lambda P
$$

Equations 1 and 2 lead to two conclusions. First, these are the same objective functions as those in a static double auction between a single worker whose type is drawn according to $G$, and a single firm whose type is drawn according to $F$, with a bargaining weight of $\Omega$ on the firm's offer. Therefore, the set of equilibria of this static double auction corresponds to the set of equilibria of our game, and the set of such equilibria satisfying A1-3 is nonempty (Satterthwaite and Williams, 1989, Theorem 3.2).

In equilibrium, for any worker with a positive probability of matching with the firm, and any firm type which matches with a positive measure set of workers, the first order conditions are, respectively:

$$
\begin{gathered}
\underline{w}_{i, 1}-\theta_{i}=\overbrace{(1-\Omega)}^{\text {direct effect }} \cdot \underbrace{\frac{1-\bar{F}\left(\underline{w}_{i, 1}\right)}{\bar{f}\left(\underline{w}_{i, 1}\right)}}_{\text {indirect effect }} \\
v-\bar{w}=\overbrace{\Omega}^{\text {direct effect }} \cdot \underbrace{\frac{\bar{G}(\bar{w})}{\bar{g}(\bar{w})}}_{\text {indirect effect }}
\end{gathered}
$$

It is both necessary and sufficient for any equilibrium satisfying A1-3 to also satisfy these two first order conditions (Satterthwaite and Williams, 1989, Theorem 3.1). The assumed monotonicity of the virtual value functions ensures that any solution of the first order conditions maximizes agents' expected payoffs. ${ }^{10}$

${ }^{10}$ Suppose $\Omega=1$ (a similar argument holds for $\Omega=0$ ). For any worker $i$ who matches with the firm with strictly positive probability (i.e. $\left.\theta_{i}<\bar{w}(1)\right)$ it must be the case that $\bar{f}\left(\underline{w}_{i, 1}\right)>0$. Therefore, $\Omega=1$ implies that $\underline{w}_{i, 1}=\theta_{i}$ which implies that $\bar{G}(x)=G(x)$ and $\bar{g}(x)=g(x)$ for all $x<\bar{w}(1)$. Equation 5 reduces to $v-\bar{w}-\frac{G(\bar{w})}{g(\bar{w})}=0$. Our assumption that $x+\frac{G(x)}{g(x)}$ is strictly increasing in $x$ implies that there is a unique $\bar{w}$ that solves this equation, and that $\bar{w}$ is a (local) maximizer. Williams (1987) shows that this is the global maximizer. Satterthwaite and 
Second, increasing the level of transparency $\Lambda$ has a similar effect as increasing the firm's bargaining weight $k$ : both increase $\Omega$, the de facto bargaining power of the firm for any $P>0$. When $\Omega=1$, each worker $i$ sets $\underline{w}_{i, 1}=\theta_{i}$, and when $\Omega=0$, the firm sets $\bar{w}=v$.

Moreover, $\Omega$ is submodular in $\Lambda$ and $k$, implying that a fixed increase in transparency is more impactful the smaller is $k$, the nominal bargaining power of the firm. When $\Lambda P=1, \Omega=1$, implying that when workers always observe peer wages and renegotiate, the nominal bargaining power $k$ does not affect the equilibrium outcome. Similarly, when the firm has all of the nominal bargaining power, i.e. $k=1$, the equilibrium outcome is constant in the level of transparency $\Lambda$. This matches our earlier description: under full transparency with common renegotiations, all workers learn $\bar{w}$ immediately and secure this wage if it is higher than their outside option, regardless of $k$. The firm therefore "posts" $\bar{w}$ knowing that all employed workers will receive this wage. When $k=1$ the firm makes an initial TIOLI offer $\bar{w}$ to each worker, and all workers with a lower outside option will be employed by the firm at this wage. Wages are "transparent" to workers in that all workers know the firm pays a common wage.

THEOREM 1. $\Omega$ is (continuously) increasing in $k, \Lambda$ and $P$, and is submodular in $k$ and $\Lambda$, submodular in $k$ and $P$, and supermodular in $\Lambda$ and $P$.

These descriptions indicate that increasing any of $k, P$, and $\Lambda$ lowers workers' de factor bargaining power, however, $k$ and $\Lambda$ are substitutes, $k$ and $P$ are substitutes, and $\Lambda$ and $P$ are complements.

\section{Decoupling transparency and renegotiation}

Our analysis thus far assumes that workers are not able to renegotiate unless they have observed the wages of their peers. We extend our model to decouple the timing of wage information and renegotiations. The extension requires moving to a continuous time model. ${ }^{11}$ Peer wage information and renegotiation opportunities arrive according to two Poisson processes, allowing workers to potentially renegotiate before and/or after observing peer wages. We allow, but do not require, the arrival rate of renegotiation opportunities to increase after peer wages are observed to capture the notion that new wage information can be used to "bring the firm back to the bargaining table."

Decoupling the arrival of information and the timing of renegotiation result in the same key connection between transparency and bargaining power: raising transparency lowers worker bargaining power. We show that analogous first-order conditions governing equilibria in our two-period model (Equations 4 and 5) hold, and the comparative statics of firm bargaining power, transparency, and renegotiation frequency have similar qualitative effects on equilibrium bargaining

Williams (1989) also extend this argument to the case of $\Omega \in(0,1)$ in the proof of their Theorem 3.1.

${ }^{11}$ Our two-period model suffers from an unrealistic lack of stationarity in such an extension: workers who do not observe peer wages before $t=2$ but are able to renegotiate will do so more aggressively knowing that there is no future possibility of observing peer wages. 
power. Therefore, our predictions on the effects of pay transparency on labor market outcomes are not limited by our assumption that workers are unable to negotiate without first observing peer wages. We present the details of this model in Appendix Section D.5.

\section{II.D. Effects of Transparency on Labor Market Outcomes}

To make predictions about labor market outcomes that we can take to the data, we select a relevant class of equilibria. We then study the effects of increasing transparency within this class of equilibria.

The monotonicity of the virtual value functions leads to a unique equilibrium when $\Omega \in\{0,1\}$ (Williams, 1987), but there exists a continuum of equilibria for $\Omega \in(0,1)$ (Satterthwaite and Williams, 1989). This multiplicity arises because the equilibrium bargaining strategies of workers and the firm are interdependent for any $\Omega \in(0,1)$; workers decide how aggressively to make initial offers depending on how the firm sets $\bar{w}$, while the firm sets $\bar{w}$ as a function of how aggressively the workers make initial offers. The set of equilibria for $\Omega \in(0,1)$ lacks natural ordering. However, experimental evidence in Radner and Schotter (1989) suggests that equilibria in which $\underline{w}_{i, 1}$ and $\bar{w}$ are linear functions of $\theta_{i}$ and $v$, respectively, are focal and most likely to be selected in practice. We similarly observe linear worker wage offers in an experimental setting (Cullen and Pakzad-Hurson, 2022).

To focus on linear equilibria, we restrict attention to a two-parameter family of power law distributions of worker outside options and firm values, and we show that this family admits a unique linear equilibrium for any $\Omega \in[0,1] .^{12}$

$$
\begin{aligned}
& F(v)=1-(1-v)^{r}, \quad r>0 \\
& G(\theta)=\theta^{s}, \quad s>0
\end{aligned}
$$

As $r$ increases, $v$ is on average lower and as $s$ increases, $\theta$ is on average higher. Therefore, increasing $r$ or $s$ reduces the average surplus from employment.

A4 $\bar{w}$ is a linear function of $v$ if there exists a worker $i$ such that $\underline{w}_{i, 1} \leq v$ according to equilibrium strategies, and $\underline{w}_{i, 1}$ is a linear function of $\theta_{i}$ for any worker $i$ such that there exists a firm type $v$ with $\theta_{i} \leq \bar{w}$ according to equilibrium strategies.

We refer to a pure strategy PBE satisfying A1-4 as a linear equilibrium. The following result extends work by Chatterjee and Samuelson (1983) who show existence of a linear equilibrium when $F$ and $G$ are uniform, corresponding to the case in which $r=s=1$.

\footnotetext{
${ }^{12}$ The approach of making parametric assumptions to ensure linear equilibrium is common. One recent example on CEO pay is Edmans et al. (2012). Power law distributions are commonly observed in economic situations such as ours, including worker income and firm productivities. See Gabaix $(2009,2016)$ for details. We note that these distributional restrictions are unnecessary for our analysis if one is only interested in comparing $\Omega=0$ to $\Omega=1$ (i.e. full secrecy with $k=0$ to full transparency and renegotiation).
} 
Proposition 2. For any pair of distributions within the family described in Equation 6 there exists a unique linear equilibrium for any $\Omega \in(0,1)$.

For the remainder of Section II.D, we consider a marketplace characterized by $r>0, s>0$ and study the impact of pay transparency in the unique linear equilibrium.

Outcomes of interest are affected by supply and demand effects as transparency rises. Workers initially offer premia over their outside options, $\underline{w}_{i, 1}-\theta_{i} \geq 0$. Similarly, the firm sets a markdown below its value for labor, $v-\bar{w} \geq 0$. We show that both $\bar{w}$ and $\underline{w}_{i, 1}$ are decreasing in the level of transparency: with increased transparency the firm reduces the highest wage offer it is willing to accept in order to mitigate information spillovers across workers (which we call the demand effect), and workers make more conservative initial offers as they anticipate they will be able to risklessly renegotiate and receive $\bar{w}$ in short order (which we call the supply effect). In an abuse of notation, let $\bar{w}_{\Omega}(\cdot)$ denote the maximum wage function of the firm and $\underline{w}_{i, 1, \Omega}(\cdot)$ the initial offer function of worker $i$ for given de facto firm bargaining power $\Omega$. The following result formalizes these effects.

Proposition 3. Consider the unique linear equilibrium given the family of distributions in Equation 6. $\bar{w}_{\Omega}(v)$ and $\underline{w}_{i, 1, \Omega}\left(\theta_{i}\right)$ are weakly decreasing functions of $\Omega$ for all $v$ and $\theta_{i}$. As $\Omega \rightarrow 0$, $\bar{w}_{\Omega}(v) \rightarrow v$ for all $v$. As $\Omega \rightarrow 1, \underline{w}_{i, 1, \Omega}\left(\theta_{i}\right) \rightarrow \theta_{i}$ for all $\theta_{i}$.

Prediction 1: Transparency lowers average wages. When transparency increases, the demand and supply effects both place downward pressure on wages. The demand effect causes the firm to reduce its maximum wage, similar to the pricing strategy of a monopsonist. This restricts the extensive margin of labor (the proportion of workers it hires) and increases the intensive margin (profit per worker hired). Simultaneously, the supply effect reduces worker initial offers, which similarly benefits the firm. The decline in average wages results in higher expected profit for the firm, and lower average worker surplus.

Although raising transparency increases the share of workers who receive wage $\bar{w}$, it lowers both $\underline{w}_{i, 1}$ and $\bar{w}$ in equilibrium. The overall effect is to shift de facto bargaining power to the firm, benefiting the firm at the expense of workers. For clear intuition, consider the extreme cases of full privacy $(\Lambda P=0, k=0)$ and full transparency $(\Lambda P=1)$. In the former, each worker makes a single TIOLI offer to the firm as no worker ever learns the wages of her coworkers, and hence, no worker will ever renegotiate. In the latter, each worker learns the wages of others within the firm and renegotiates. Therefore, every employed worker will demand and receive exactly $\bar{w}$, which is equivalent to the firm making a single TIOLI offer to all workers. The main result of Williams (1987) implies that each party prefers to be the one making the once-and-for-all offer to the other, as that party maximizes their expected surplus.

THEOREM 2. Consider the unique linear equilibrium given the family of distributions in Equation 6. In expectation (over firm types), the equilibrium profit of the firm is strictly increasing in $\Omega$, 
and the average equilibrium surplus of workers and average wages conditional on employment are strictly decreasing in $\Omega$.

Prediction 2: Partial transparency maximizes employment when workers have sufficiently high individual bargaining power. When transparency increases, raising the de facto firm bargaining power from $\Omega^{\prime}$ to $\Omega^{\prime \prime}$, the demand effect lowers the equilibrium level of employment while the supply effect raises it. $\bar{w}_{\Omega^{\prime \prime}}(v) \leq \bar{w}_{\Omega^{\prime}}(v)$ for all $v$ implies there are fewer workers with $\theta_{i} \leq \bar{w}_{\Omega^{\prime \prime}}(v)$, and therefore fewer workers who are eligible for employment. Meanwhile, $\underline{w}_{i, 1, \Omega^{\prime \prime}}(\theta) \leq$ $\underline{w}_{i, 1, \Omega^{\prime}}(\theta)$ for all $\theta$, implying that fewer workers over-negotiate by initially offering $\underline{w}_{i, 1, \Omega^{\prime \prime}}(\theta)>\bar{w}_{\Omega^{\prime}}(v)$. The primary cause of unemployment when $\Omega$ is low is workers act too much like monopolists in initial negotiations, and when $\Omega$ is high, the firm acts too much like a monopsonist. We show that employment is single-peaked in the level of transparency: a more even split of the de facto bargaining power is employment maximizing, and either full privacy or full transparency is employment minimizing.

THEOREM 3. Consider the unique linear equilibrium given the family of distributions in Equation 6. The expected proportion of workers hired in equilibrium is concave in $\Omega$ and is maximized at $\Omega^{*}=\frac{r+1}{r+s+2}$. Moreover, the ex-post employment level is submodular in $v$ and $\Omega$ for the set of firm types that hire a positive measure of workers. ${ }^{13}$

One implication that is useful for our empirical analysis is the connection between the employment level and the composition of the workforce. For any $\Omega, v$ there exists some cutoff $\theta(\Omega, v)$ such that a worker $i$ is employed by the firm (i.e. $\left.i \in I_{2}\right)$ if and only if $\theta_{i} \leq \theta(\Omega, v)$. Therefore, if the level of employment is the same under $\Omega^{\prime \prime}$ and $\Omega^{\prime}$ with $\Omega^{\prime \prime}>\Omega^{\prime}$, then it must be the case that $\theta\left(\Omega^{\prime}, v\right)=\theta\left(\Omega^{\prime \prime}, v\right)$. In other words, marginally employed workers always have higher outside options than inframarginal workers. Therefore, if employment rises (falls, remains constant) in transparency, high outside option workers join (leave, do not transition in or out of) the workforce.

We offer a comment on social surplus: due to the cutoff structure of employment, the ex-post maximizer of the employment level also maximizes ex-post social surplus. Because each employed worker earns a wage weakly greater than her outside option, in equilibrium almost every employed worker increases social surplus by $v-\theta_{i}>0$, implying that social surplus is strictly increasing in the level of employment. Therefore, $\Omega^{\prime \prime}$ results in increased ex-post social surplus compared to $\Omega^{\prime}$ if and only if $v$ is below some threshold, due to the submodularity of employment in $v$ and $\Omega$.

Prediction 3: Transparency's effects are muted when workers have low individual bargaining power. Consider two bargaining weights $k^{\prime \prime}>k^{\prime}$ and two levels of transparency $\Lambda^{\prime \prime}>\Lambda^{\prime}$. For any fixed $P>0$, take the four resulting combinations of de facto bargaining

\footnotetext{
${ }^{13}$ For the family of distributions in Equation 6, the expected employment maximizing level of firm de facto bargaining power can be rewritten $\Omega^{*}=\frac{1-\mathbb{E}(\theta)}{1+\mathbb{E}(v)-\mathbb{E}(\theta)}$.
} 
power from Equation 3: $\Omega_{1}=k^{\prime}+\left(1-k^{\prime}\right) \Lambda^{\prime} P$ (high individual worker bargaining power, low transparency), $\Omega_{2}=k^{\prime}+\left(1-k^{\prime}\right) \Lambda^{\prime \prime} P$ (high individual worker bargaining power, high transparency), $\Omega_{3}=k^{\prime \prime}+\left(1-k^{\prime \prime}\right) \Lambda^{\prime} P$ (low individual worker bargaining power, low transparency), $\Omega_{4}=k^{\prime \prime}+\left(1-k^{\prime \prime}\right) \Lambda^{\prime \prime} P$ (low individual worker bargaining power, high transparency). Theorem 1 implies that $\Omega_{2}-\Omega_{1}>\Omega_{4}-\Omega_{3} \geq 0$; de facto firm bargaining power is more responsive to an increase in transparency under $k^{\prime}$, than $k^{\prime \prime}$. Combining this with Theorem 2 yields the following conclusion:

COROLlary 1. Consider the unique linear equilibrium given the family of distributions in Equation 6. For any $P>0$, an increase in transparency from $\Lambda^{\prime}$ to $\Lambda^{\prime \prime}>\Lambda^{\prime}$ will result in smaller declines in expected average wages the larger is $k$.

If workers have no bargaining power $(k=1)$, transparency will have no effect on the equilibrium outcome. Note that our parameter $k$ captures individual bargaining power, not overall worker bargaining power. In Appendix Section D.2 we formally model how collective bargaining agreements may similarly strip workers of individual bargaining power even if (collectively) workers have high bargaining power. We show that the level of pay transparency will have no effect on average wages in our collective bargaining model, analogous to the case in our base model where $k=1$.

\section{Prediction 4: Transparency compresses wages within marketplaces, but not neces-} sarily across marketplaces. To understand the effects of transparency on compression within a marketplace, we consider the relative effect of transparency on different workers. To fix intuition, assume $k=0$ and $P>0$, and take two levels of transparency $\Lambda^{\prime}$ and $\Lambda^{\prime \prime}$, where $\Lambda^{\prime}<\Lambda^{\prime \prime}$, corresponding to $\Omega^{\prime}$ and $\Omega^{\prime \prime}$, respectively, where $\Omega^{\prime}<\Omega^{\prime \prime}$. Consider the difference in earnings of two workers $i$ and $j$, with outside options $\theta_{i}>\theta_{j}$ who are hired under both $\Omega^{\prime}$ and $\Omega^{\prime \prime}$. There are two effects when moving from $\Omega^{\prime}$ to $\Omega^{\prime \prime}$. First, the supply effect incentivizes both workers to reduce initial wage offers. We find that in equilibrium, since $j$ has a lower outside option than $i, j$ reduces her initial offer more than $i$, increasing the initial wage gap between $i$ and $j\left(\underline{w}_{i, 1, \Omega^{\prime \prime}}-\underline{w}_{j, 1, \Omega^{\prime \prime}}>\underline{w}_{i, 1, \Omega^{\prime}}-\underline{w}_{j, 1, \Omega^{\prime}}\right.$ for $\Omega^{\prime \prime}>\Omega^{\prime}$ ). Second, higher transparency increases the probability that both workers renegotiate, reducing dispersion of their earnings as $\bar{w}_{\Omega}-\underline{w}_{j, 1, \Omega}>\bar{w}_{\Omega}-\underline{w}_{i, 1, \Omega}$ for all $\Omega<1$. The compressing effect of renegotiation overwhelms the increased dispersion from the supply effect, leading to more equal wages between $i$ and $j$. The following statement formalizes this point for any $k$.

THEOREM 4. Consider the unique linear equilibrium given the family of distributions in Equation 6. Let $\theta_{i}>\theta_{j}$, and $\Omega^{\prime \prime}>\Omega^{\prime}$. For almost all workers $i$ and $j$ hired in equilibrium under both $\Omega^{\prime}$ and $\Omega^{\prime \prime}$. Then for any $v$, the difference in expected wages between $i$ and $j$ is smaller under $\Omega^{\prime \prime}$ than $\Omega^{\prime}$, and converges to zero as $\Omega^{\prime \prime} \rightarrow 1$.

Theorem 4 can also be used to study transparency's effect on wages across groups of workers within a marketplace. In Appendix Section D.3 we derive a condition under which transparency 
closes the gender pay gap. However, this result cannot be applied to workers (or groups of workers) across marketplaces. These effects do not aggregate across marketplaces because parameters $r$ and $s$ mediate the degree of wage compression within each marketplace. For example, suppose that in the market for nurses $s$ is very large (i.e. workers typically have high reservation wages) and $r$ is large (i.e. a firm typically has low marginal revenue product from labor), while in the market for miners $s$ is small and $r$ is large. We expect transparency to compress wages within each marketplace. However, under these parameterizations, the scope for wage reduction is smaller among the workers who start out with higher wages, nurses. As a result, when aggregating these two markets, we could observe greater dispersion in wages following a transparency mandate.

Wage compression does not necessarily follow even for similar workers within more narrowly defined labor markets. Continuing our example, even among nurses in the same geographic area, it may be known that hospitals typically have higher values for labor (i.e. $r$ is small) while long-term-care facilities typically have lower values for labor ( $r$ is large). Therefore, given the identity of the firm, bargaining strategies of workers and the firm will vary, leading to heterogeneous wage decreases in transparency even within what might typically be considered the same "labor market," thus clouding within-marketplace compression forces. We discuss the distinction between within and across marketplace compression more fully in Appendix Section A.9.

\section{II.E. Endogenous transparency and the role of legislation}

We have thus far assumed transparency is exogenously set at a common level for all firm types. In reality, a firm may have the ability to select its own level of transparency. In this section, we discuss a game in which the firm selects the level of transparency after observing its value $v$. For compactness, we make the firm's choice of transparency unobserved by workers during initial wage negotiations due to "cheap talk" forces; initial announcements by the firm regarding its level of transparency will not be credible and will be ignored by workers. ${ }^{14}$

Formally, the endogenous transparency game proceeds as follows. Prior to workers arriving at $t=1$, the firm observes $v$ and simultaneously selects its maximum wage $\bar{w} \in[0,1]$ and its level of transparency $\Lambda \in[\underline{\Lambda}, 1]$. The minimum allowable level of transparency by law is $\underline{\Lambda} \in[0,1)$, and is common knowledge between the firm and all workers. However, workers do not observe the firm's selected level of transparency $\Lambda$ at the time of the initial negotiation. The game then proceeds as in our base model.

\footnotetext{
${ }^{14}$ While firms may benefit from making an announcement of high transparency in $t=1$ to secure the lowest wage offers, in $t=2$ all firms types have an incentive to break their promise in order to avoid costly renegotiations. Because of this undercutting incentive, the announcement in $t=1$ is "cheap talk" to workers. One real-world company that "credibly" promises high levels of transparency is Buffer. Buffer has built a salary-formula app into its website that allows employees to "test" their own salaries and discover those of others as a function of observables. Of course, such technology may come with other costs (e.g. a rigid wage structure, and broadcasting wages to competing firms) which may make it infeasible for most firms.
} 
Proposition 4. Let $k<1$ and $P>0 . \Lambda=\underline{\Lambda}$ in any equilibrium of the endogenous transparency game, regardless of the value of the firm.

In equilibrium, no firm type will pick a level of transparency that is higher than the minimum level allowed by law, $\underline{\Lambda}$. The unobservability of the selected level of transparency removes commitment power a firm obtains from higher transparency in our base model. In any candidate equilibrium in which the firm selects $(\Lambda, \bar{w})$ where $\Lambda \in(\underline{\Lambda}, 1]$, the firm has a profitable deviation to $(\underline{\Lambda}, \bar{w})$. All workers make initial offers as if $\Lambda=\underline{\Lambda}$. The firm will therefore employ the same set of workers at the same initial wages. And, by selecting $\underline{\Lambda}$, the firm avoids costly renegotiations with $(1-k) P(\Lambda-\underline{\Lambda})$ fraction of workers that it employs. ${ }^{15}$

The logic of this result extends even if workers receive a partially-informative signal of the firm's chosen level of transparency (possibly from a third-party source or the firm's reputation from unmodeled previous generations of workers). Let each worker receive a signal of the firm's choice of transparency at $t=1$ prior to initial negotiations, where the signal is drawn with full support over $[0,1]$ and the distribution from which the signal is drawn (potentially) varies based on the chosen $\Lambda$. For $k<1$ and $P>0$, there remains an equilibrium in which the firm selects $\Lambda=\underline{\Lambda}$ for all $v$. Moreover, similar reasoning implies this is the unique pooling equilibrium in which the firm selects the same level of transparency with probability one for all $v$.

The implication of Proposition 4 is that a law increasing the minimum-allowable transparency from $\underline{\Lambda}$ to $\underline{\Lambda}^{\prime}$ will have the same effect as increasing the exogenous level of transparency from $\underline{\Lambda}$ to $\underline{\Lambda}^{\prime}$ in our base model. In Section III.A we present evidence of the impact of U.S. state laws which prohibit employers from retaliating against workers who discuss their own wages with peers, or inquire as to the wages of coworkers.

\section{II.F. Extensions and Dynamic Considerations}

We present extensions of our model to study additional dynamic considerations of pay transparency. In Appendix Section D.6 we expand our model to allow workers to search for work across multiple firms, and show that many results are robust to this extension. In Appendix Section D.7 we consider a setting with previously employed workers and downward nominal wage rigidity, and we describe the transition path to a steady state equilibrium following an unexpected change in the level of pay transparency.

\footnotetext{
${ }^{15}$ We have not formally modeled the choice of workers to "bury their heads in the sand" and ignore wage information. Nevertheless, a richer model that allows each worker to ignore information would lead each worker to seek out wage information to the fullest extent allowed by the firm: for fixed $\bar{w}$ higher transparency helps workers at the point of (re)negotiation. Because each worker has zero measure, no single worker will affect the equilibrium payoff, and therefore actions, of the firm.
} 


\section{EMPIRICAL EVIDENCE}

We empirically test our model predictions, Theorem 2 and Corollary 1. Where model predictions are ambiguous, we seek empirical answers, as is the case for Theorem 3.

\section{III.A. "Right of Workers to Talk" (ROWTT) U.S. State Laws}

We study the enactment of legislation setting a minimum level of transparency through strong protections for coworkers who discuss pay with each other, which we refer to as "Right of Workers to Talk" (ROWTT) laws. As early as 1935, a clause in the National Labor Relations Act (NLRA) established worker rights to discuss pay, a central part of labor organizing; however, these protections were described in very general terms-"protecting concerted activity"-and violators did not face punitive damages, which led to the critique of the NLRA as a "toothless tiger" (Green, 2014). Stansbury (2021) finds the NLRA did not create sufficient incentives for firms to comply. More recently, individual U.S. states have enacted ROWTT laws, purportedly to combat discriminatory pay. These laws prohibit employers from retaliating against workers who discuss or inquire about coworker pay, with a clear enforcement mechanism: financial penalties to employers who violate the provisions. All state ROWTTs newly allow workers to sue employers in violation of ROWTT, ${ }^{16}$ and all ROWTT laws prescribe punitive damages and/or fines for employers found in violation.

These laws received bipartisan support; both Republican and Democratic governors signed ROWTT bills into law. ${ }^{17}$ In 2016, Executive Order 13665 came into effect, extending ROWTT protections to employees of federal contractors (Federal Register, 2015), which collectively employ roughly $25 \%$ of U.S. workers. ${ }^{18}$ In Figure I we provide a timeline and geographical depiction of the enactment of each state law. There are 13 such policies in our study window (2000-2016), spanning the West, Northeast, Mid-Atlantic, and Midwest regions, but excluding the South. While ROWTT laws vary in their precise language, all legislation included in our analysis protect the right of workers to disclose their own salary and inquire about the salaries of others, and apply to all workers with few exceptions, such as HR representatives. Additional information about the collection of ROWTT polices and links to each state's legislation is available in Appendix Section A.1.

\section{III.A.1. Transparency mandates' effect on perceived rights to discuss pay}

Our theory defines transparency as the rate that employees learn about the pay of their coworkers. Ideally we would have a direct measure of how communication about pay between coworkers changed before and after protections were enacted. While we cannot directly observe

${ }^{16}$ D.C.'s ROWTT is the only one that requires complaints be adjudicated by the labor board.

${ }^{17} 12$ Democrats, 5 Republicans, and 1 Independent governor signed these policies into legislation.

${ }^{18}$ See https://uhr.umd.edu/wp-content/uploads/Workplace_Rights_JRF_QA_508c.pdf for a discussion on the share of workers employed by federal contractors. 
this, we have gained access to a repeated survey conducted by the Institute for Womens' Policy Research, along with Jake Rosenthal at the University of Washington. The two waves of this survey (2010, 2017/8) included a question about whether the employer prohibited discussions about pay, offering two snapshots of the share of U.S. workers in the private sector who believe their employers prohibited discussions with other co-workers about pay. ${ }^{19}$ Between these two waves, 11 states enacted ROWTT. Figure II illustrates the share of employees who claimed their employer prohibited them from discussing pay in each survey wave, across states that did and did not enact an ROWTT between waves. In states that enacted an ROWTT between survey waves, the share fell from $33.2 \%$ to $9.9 \%$, while in the remaining states the share fell from $24.2 \%$ to $18.6 \%$, indicating large and statistically significant differences between states with and without protections by 2017 (p-value $<0.001$ ), as well as significant differences in trajectories (p-value $<0.001) .{ }^{20}$ Anecdotally, these additional protections from ROWTTs increased the sharing of salary information. One journalist tracked down salary spreadsheets shared by employees among museum professionals, baristas, journalists, ad agency staffers, and public interest lawyers, generating the headline: "The Google spreadsheet was the most powerful labor tool in 2019" (Reyes, 2019).

\section{III.A.2. Outcome data and sources}

We use data from the American Community Survey (ACS) to track wages and employment between 2000 and 2016. Starting in 2000, the ACS surveyed more than 3 million individuals annually, allowing us to identify 5,452,696 individuals working in states that enact ROWTT laws during our window of analysis. The ACS contains information on hours worked per week, weeks worked per year, sector, occupation, industry, U.S. state of work, and demographic characteristics, in addition to annual earnings information with a cap equal to the 99.5th percentile in each state. ${ }^{21}$ We complement the main ACS sample with a measure of union coverage from the Current Population Survey (CPS). We merge in unionization at the occupation level using the standardized 1990 occupation codes provided by Flood et al. (2020) and Ruggles et al. (2021).

In Table A.2 we present summary statistics on our combined sample. Panel A presents summary statistics exclusively for private-sector full-time employees who are prime-age, while Panel B presents summary statistics for the full prime-aged sample.

\section{III.A.3. Empirical Strategy}

We carry out a multi-period difference-in-difference design, often referred to as an event-study analysis. We follow Donohue III and Heckman (1991) and use neither event data nor outcome data after 2016, when complementary federal policies are enacted.

\footnotetext{
${ }^{19}$ See Hegewisch et al. (2011) and Sun et al. (2021) for details about these survey waves.

${ }^{20}$ The national trend may reflect the enactment of protections for all employees of federal contract workers in 2016.

${ }^{21}$ See https://usa.ipums.org/usa-action/variables/INCWAGE\#codes_sec.
} 
Our key identifying assumption is that the precise timing of ROWTT enactment during our 12-year window, among states that eventually pass ROWTT laws, is uncorrelated with underlying wage and employment dynamics. We empirically test this assumption by examining how wages, employment and additional labor market features evolve in each state leading up to the enactment of ROWTT. Under the presumption that the states that eventually pass ROWTT laws are more similar along unobservables than states that do not pass these laws, our baseline specification excludes states that never enact ROWTT from our analysis. ${ }^{22}$

In our baseline specification, we also assume that the effect of transparency is homogeneous across cohorts. ${ }^{23}$ As a robustness check we relax our assumption about homogeneous treatment effects and estimate the effect of each cohort separately before calculating the weighted average to determine the average treatment effect.

Across all specifications we restrict our sample to prime working-age individuals, ages 25 to 54 , employed full-time in the private sector. ${ }^{24}$ The reason we focus exclusively on the private sector is that many local laws made salaries public information for government workers before ROWTT protections were enacted state wide. ${ }^{25}$ We discuss the effect of ROWTT in the public sector further in Appendix Section A.2.

We estimate the dynamic effect of ROWTT laws over the three years following their enactment. We also estimate the dynamic effect of ROWTT laws over the six years prior to their enactment as a test of whether enactment was precipitated by any underlying events that could co-move with our outcomes of interest, such as a rise in pro-business sentiment and related policies.

We estimate the following multi-period difference-in-differences specification:

$$
\begin{aligned}
y_{i s t}= & \alpha_{s}+\sum_{\ell=-6}^{-2} \beta_{\ell} \mathbf{1}\left\{t-E_{s}=\ell\right\}+\sum_{\ell=0}^{3} \beta_{\ell} \mathbf{1}\left\{t-E_{s}=\ell\right\}+ \\
& \gamma \mathbf{1}\left\{t-E_{s}<-6\right\}+\delta \mathbf{1}\left\{t-E_{s}>3\right\}+\boldsymbol{\lambda} \boldsymbol{X}_{\text {ist }}+\epsilon_{i s t}
\end{aligned}
$$

where $i$ indexes individuals, $s$ indexes state of employment and $t$ indexes year. In our main specification, $y_{i s t}$ is the logarithm of annual wage income or an indicator for worker $i$ 's full-time

\footnotetext{
${ }^{22}$ We recognize trade-offs in making this choice. Excluding untreated states reduces power and introduces potential for colinearity between year fixed effects and linear treatment effects. While we expect our effects are non-linear (discontinuous around the year of the event) and hence, our estimation less susceptible to this colinearity, we verify this by replicating the analysis using our final cohort as a pure set of control states as well as adding back in states that never pass ROWTT.

${ }^{23}$ If effects differed by cohort, the multi-period difference-in-differences estimation strategy might result in a biased estimate of the average treatment effect across cohorts.

${ }^{24}$ We consider a worker to be employed full-time if they self-report that they usually work at least 35 hours/week and work for at least 48 weeks in the last year.

${ }^{25}$ For example, in California two-thirds of cities independently chose to disclose the compensation of city employees prior to a 2010 mandate to disclose salaries of all municipal employees (Mas, 2017).
} 
employment status in the private sector. $\alpha_{s}$ is a state fixed effect and $E_{s}$ is the year when state $s$ enacts the ROWTT policy. Thus, $t-E_{s}$ indexes years relative to the event. $\ell=-1$ is the omitted reference period, $\gamma$ and $\delta$ are indicators for periods outside the event window. $\boldsymbol{X}_{i s t}$ is a vector of controls that include age (quadratic), education, year-by-industry (NAICS 3-digit) and yearby-occupation (SOC 3-digit) indicators. We allow for interactions between available demographic characteristics, namely marital status, race and gender, and we allow region-by-industry effects to differ by gender. Standard errors are two-way clustered by state and year.

In our baseline specification, we report the results from a balanced composition of states in the years following the enactment of the law. We report post-period effects for states with events through 2013 by including the following interaction term in Equation 7:

$$
\sum_{\ell=0}^{3} \beta_{\ell}^{*} \mathbf{1}\left\{t-E_{s}=\ell\right\} \times \mathbf{1}\left\{E_{s} \leq 2013\right\} .
$$

In a series of robustness tests we include year-by-Census-division fixed effects $\alpha_{t r}$, and we weight our sample to estimate a counterfactual where the composition of workers in each education-genderstate cell remains fixed throughout the post period. ${ }^{26}$ To relax our assumption of homogeneous treatment effects across cohorts, we allow treatment effects to vary depending on the year ROWTT is enacted, and calculate the weighted average of each year-specific treatment effect. We implement this using the interaction-weighted estimator, first proposed by Gibbons et al. (2019) and refined by Sun and Abraham (2020). This estimator is designed to recover average treatment effects even in the presence of underlying heterogeneity across years. We include the full specification and estimation details in Appendix Section A.3.

We estimate the heterogeneous effects of ROWTT separately for occupations in which workers have a relatively high versus low degree of individual bargaining power. Corollary 1 predicts wage declines are muted when workers have low individual bargaining power, indicated by take-it-orleave-it (TIOLI) job offers. We zero in on two of the best known predictors of TIOLI offers, low education and union membership (Hall and Krueger, 2012). ${ }^{27}$ In Equation 8 we add interaction terms to indicate low individual bargaining power, first proxied by whether the individual does not have a 4-year college degree, and second, by whether the individual's occupation has above the median unionization rate of $7 \%$.

\footnotetext{
${ }^{26}$ We take the year before the policy is enacted as the reference year and estimate the educational distribution of each state separately for men and women. Within each state, we then reweight the sample in every other year to match the education-by-gender distribution in the reference year.

${ }^{27}$ Those with 4-year college degrees are 1.5 times as likely to bargain as those without), and being a union member (non-union members are 2.3 times as likely to bargain as unionized workers). Education and unionization are the two univariate factors most closely associated with TIOLI job offers. See Hall and Krueger (2012), Table 3 for details.
} 


$$
\begin{aligned}
& \sum_{\ell=-6}^{-2} \beta_{\ell} \mathbf{1}\left\{t-E_{s}=\ell\right\} \times \mathbf{1}\{\text { low individual barg.power }\}+\sum_{\ell=0}^{3} \beta_{\ell} \mathbf{1}\left\{t-E_{s}=w\right\} \times \mathbf{1}\{\text { low individual barg.power }\}+ \\
& \gamma \mathbf{1}\left\{t-E_{s}<-6\right\} \times \mathbf{1}\{\text { low individual barg.power }\}+\delta \mathbf{1}\left\{t-E_{s}>3\right\} \times \mathbf{1}\{\text { low individual barg.power }\}
\end{aligned}
$$

\section{III.A.4. Results}

Figure III graphically presents our estimates of $\beta_{\ell}$ from Equation 7 . The event-study graph shows the evolution of log wages (Panel A) and private sector employment (Panel B) in each of the six years leading up to the enactment of ROWTT and three years after enactment. The year before the event (-1) corresponds to the omitted category, and thus the corresponding coefficient is always zero by construction. The range along the y-axis has been set to approximately +/1 standard deviation in average wages over time, within state.

Coefficient estimates in Figure III, Panel A represent wage differences relative to the period prior to ROWTT enactment, and calendar-year fixed effects absorb time trends. As a result, a coefficient estimate of zero does not imply that wages remain stagnant in nominal terms; rather, it indicates similar growth rates of wages in states leading up to the enactment of ROWTT. In the six years leading up to the enactment of ROWTT, coefficients are precisely estimated and statistically indistinguishable from zero, suggesting that our assumption of parallel trends in wages holds.

By contrast to the period before enactment, the post-ROWTT evolution of wages diverges from the wage path of states that have yet to enact ROWTT. One year after enactment, wages are $2.2 \%$ lower ( $\mathrm{p}$-value $<0.001$ ) or roughly a fifth of a standard deviation in state-level average wages over the years. By three years after enactment, wages are $2.7 \%$ lower ( $\mathrm{p}$-value $=0.019$ ) than the period prior to enactment. Over the entire post-treatment period, including the year of enactment, wages decline by $1.8 \%$ ( $\mathrm{p}$-value $=0.003$ ).

The decline in real wages we observe is consistent with a slowing of nominal wage growth after enactment of ROWTT. If firms had fixed nominal wages during the window we examine, year over year employees would have experienced a decline in real wages, on average, by approximately $2.8 \%{ }^{28}$ The single, discontinuous "step down" in relative wages that we observe in the year after enactment is rationalized in a model of the dynamic transition of wages in the presence of downward nominal wage rigidity (as documented in Bewley, 1999; Grigsby et al., 2021) and inflation. ${ }^{29}$

In Table I, Panel A, we report the results of several alternative specifications to our baseline model of wage effects. We report the dynamic effects around ROWTT enactment, and we also

\footnotetext{
${ }^{28}$ According to https://www.ssa.gov/oact/cola/central.html, nation-wide average wages rise nominally by an average of $2.8 \%$ each year from 2004-2016.

${ }^{29}$ For details on this model, see Appendix Section D.7.
} 
report the average of the post-treatment period. The stability of estimates across specifications corroborate the baseline estimate of the wage decline. In Col. 1, we present our baseline results, the multiperiod difference-in-differences estimator with a fixed composition of states in the post period. In Col. 2, we drop our restriction for a balanced composition of states and allow all cohorts (2004-2016) to contribute to all periods for which the data are available. The post event coefficients exhibit nearly identical results as our baseline, and average $-1.6 \%(\mathrm{p}$-value $=0.019)$ in the post-treatment period. In Col. 3 we include region-by-year fixed effects using detailed Census divisions, effectively restricting comparisons between states to neighboring states. The average post-treatment effect is $-1.7 \%$ $(\mathrm{p}$-value $=0.079)$. In Col. 4 , we re-weight observations to maintain a fixed composition of workers within education-by-gender cells over time, illuminating whether the exit or entry of different types of workers drives wage reductions. The average post-treatment effect remains largely unchanged at $-1.6 \%$ ( $p$-value $=0.003$. Finally, we compute the Sun-Abraham interaction-weighted estimator which relaxes our assumption of homogeneous treatment effects across cohorts, as described in Appendix Section A.3. The average post-treatment point estimate is $-2.3 \%$ ( $\mathrm{p}$-value $<0.001$ ), suggesting a slightly larger decline in wages but still statistically indistinguishable from our baseline estimate. Across all specifications, wages appear to follow parallel trajectories leading up to ROWTT enactment. For each of these specifications, we report the p-values associated with our average treatment effect, taking the mean post-treatment effect and subtracting the mean pre-treatment effect. We calculate p-values using the cluster-robust variance estimator (CRVE), as well as using wild cluster bootstrap with randomization inference (WBRI) proposed by MacKinnon and Webb (2017). The latter procedure accommodates a small number of clusters and heterogeneously sized clusters. WBRI p-values broadly confirm statistical significance of our treatment effects, but offer a more conservative account of the precision achieved across our specifications. When using cluster-level collapsed estimates (Donald and Lang, 2007), precision lies between CRVE and WBRI estimates. ${ }^{30}$

Wage declines could partially stem from a change in employment resulting from ROWTT. If high-paid workers disproportionately leave the private sector after ROWTT, or if low-paid workers disproportionately join the private sector, average wages would fall even if no wages are renegotiated. We present estimates of the effect of ROWTT on private sector employment in Panel B of Figure III. We plot estimated coefficients from the same event study specification as Panel A, replacing our dependent variable with an indicator for full-time employment in the private sector. The range of our y-axis is set to match Panel $\mathrm{A},+/-1$ standard deviation in average wages over time, to visually aid comparison in the assessment of employment's role in wage changes. Our point estimates suggest that employment in the private sector remains constant leading up to ROWTT enactment, and subsequently rises modestly with an average treatment effect of $0.5 \%$ (p-value

\footnotetext{
${ }^{30}$ In Appendix Section A.4 we expand Table I to include our cluster-level collapsed specification (Donald and Lang, 2007), and we provide further details on wild cluster bootstrap procedures using randomization inference (MacKinnon and Webb, 2019, 2020).
} 
$=0.108$ ). Table I, Panel B reveals that these point estimates are stable across specifications, and only marginally statistically distinguishable from zero. When we apply the wild cluster bootstrap with randomization inference, we cannot reject that ROWTT laws have zero effect on private sector employment. Nonetheless, an effect of $0.5 \%$ would represent an .29 standard deviation change in private sector employment within state over this period. For that reason, we take further steps to bound the potential role of composition changes in lowering average wages.

In the spirit of Lee (2009), we liberally bound the effect that additional workers could have on lowering average wages by assuming an employment shift equal to the upper $95 \%$ confidence interval of our estimates, and attributing the entirety of the employment shift to new workers who earn zero wages. Employment changes account for less than one-third the adjustment to wages following ROWTT. ${ }^{31}$ We also carry out additional bounding exercises in Appendix Section A.5, allowing for reallocation of employed workers across different firm types, which corroborate that only a fraction of the observed wage effects could be driven by composition changes. The results from these additional bounding exercises are consistent with the re-weighting exercise we carry out in Table I, Col. 4 which finds that differential exit and entry of workers across gender-by-education cells do not drive wage declines. We conclude that composition changes do not account for the entirety of our estimated wage effects. ${ }^{32}$

In Figure IV, Panel A, we report the dynamic wage effects for private sector employees with, and without, a 4-year college degree separately, following Equations 7 and 8. In Panel B we plot the difference between the effects for those with and without a 4-year college degree. Leading up to the enactment of ROWTT, wages follow the same trajectory irrespective of educational attainment. Starting the year that ROWTT policies are enacted, wages between these groups diverge. Among those without a college degree, wages stay relatively constant throughout the post-period, falling on average $1.0 \%$ ( $\mathrm{p}$-value $=0.213$ ) over the entire post period. By one year after enactment, wages fall by 3.1 pp more among those with a college degree than those without ( $\mathrm{p}$-value=0.108), and the gap persists. Over the post period, those with a college degree experience a wage decline on average of $3.2 \%$ ( $\mathrm{p}$-value $=0.019)$. We show the same pattern across more granular education bins in Appendix Section A.6. We also we show that the private sector employment of the different education groups follow the same trajectory following ROWTT enactment in Appendix Section A.8. These results offer suggestive evidence that individuals with higher education, and thus likely higher individual bargaining power, face steeper effects of pay transparency on wages.

\footnotetext{
${ }^{31}$ Let $\epsilon$ be the employment share increase and let $A$ be the average wages prior to ROWTT. We bound the (log point) decrease in wages due to employment increases by $\frac{\frac{A+0 \cdot \epsilon}{(1+\epsilon)}-A}{A}=-\frac{\epsilon}{1+\epsilon}$. Table I Col. 1 reports the upper $95 \%$ confidence interval for employment share increases to be 0.006 . Picking $\epsilon=0.006$ to maximize the absolute value of this bound leads to an effect size of $-0.0059 \log$ points, which accounts for less than one-third of the effect size of ROWTT on wages. In summary, our exercise reveals that a 1 pp increase in employment can account for no more than a 1 pp decrease in average wages.

${ }^{32}$ In Section II.D, we describe theoretical reasons why the observed composition changes would lead us to underestimate, rather than overestimate, the wage decline.
} 
In Figure V, we report the wage effect for above- and below-median rates of unionization at the occupation level. In Figure V Panel A we plot the dynamic effects of ROWTT for occupations with above and below the median share of unionized workers, also estimated following Equations 7 and 8. In Panel B we plot the difference between the effects for occupations with low and high rates of unionization. Wages in high and low unionized occupations follow the same path until the year that ROWTT policies are enacted. Among relatively unionized occupations, wages fall by $1.4 \%(p$-value $=0.085)$ one year after enactment and remain at $1.5 \%(p$-value $=0.264)$ three years after enactment. For occupations with relatively low rates of unionization, wages decline nearly twice as much, an additional $1.8 \mathrm{pp}$ (p-value=0.001) over the post-period window, and experience wage declines of $3.4 \%$ ( $\mathrm{p}$-value $=0.005)$ three years after enactment. In Appendix Section A.7 we show the average post treatment effect gradually rises as unionization rates fall from $20 \%$ in the upper quartile down to $2 \%$ in the bottom quartile. We show in Appendix Section A.8 that employment trajectories do not diverge post ROWTT. These results suggest that collective bargaining agreements that reduce individual bargaining power also mitigate the effects of pay transparency on the bargaining position of workers.

When interpreting our heterogeneous treatment effects, it is important to consider alternative interpretations to the causal relationship we present. While our theory predicts a causal relationship, our empirical test does not rule out the possibility that individuals with a college degree are different from those without one in ways that affect wage negotiations, and mediate the impact of transparency, yet are unrelated to relative bargaining power. Similarly, occupations with higher rates of unionization are different along dimensions that could mute the effects of ROWTT but are orthogonal to individual bargaining power. For example, occupations with higher rates of unionization could be associated with institutions that do not adapt quickly to changes in the labor market or operate in less mobile labor markets; hence, they may be slower to adjust their wage trajectories and do not do so within our window of observation. Alternatively, the policy itself could have been enforced differently among high-educated workers or within occupations that have higher rates of unionization. In Section III.B, we strengthen our empirical test of the role of bargaining power by exploring the relationship between unionization and transparency's effect across a wide range of labor markets, with distinct institutions for collective bargaining.

Our model corroborates the intuition of policy makers that transparency compresses wages between similar workers within a firm. However, our empirical setting is not the ideal place to test this prediction as we do not observe firm-worker links and our data are cross-sectional in nature. In Appendix Section A.9, we present the formal theoretical reasons for limited comparisons even within labor market. However, other studies have shown compression within firm among comparable workers follow pay transparency mandates. We review these studies in Section III.B. 


\section{III.A.5. Main Threats to Internal Validity}

Inherent in our empirical strategy are several assumptions. The first is that ROWTT laws are enacted in isolation; in other words, these policies are not coupled with additional legislation or timed around another noteworthy event. We have reason to believe this is the case. While nearly all ROWTT legislation are amendments to existing equal pay laws, in only four cases is there arguably related legislation enacted around the same time. ${ }^{33}$ Our results are robust to excluding these four events.

Relatedly, we assume the choice to enact ROWTT is not driven by changes that are already underway, in essence a story of reverse causality whereby declining wages leads to the enactment of ROWTT, rather than the other way around. Reverse causality is typically less of a concern when effects are discontinuous and occur after the policy is enacted; nevertheless, we also collect facts about the motivation for the passage of ROWTT laws. More than three-quarters of the ROWTT policies refer to pay discrimination in the title or preamble describing the law (the partial equilibrium narrative), and nowhere is there mention of wage levels.

We also consider the possibility that a third factor leads to both declining wages and the enactment of ROWTT. We could, in principle, be detecting a rapid shift in sentiment in favor of businesses that, either through policies or atmosphere, effectively shifts bargaining power towards firms and simultaneously leads to the enactment of ROWTT. Or alternatively a shift in sentiment in favor of labor and related policies (including ROWTT) intended to combat inequality and yet, inadvertently, also lowers average wages. To test whether there exist concurrent shifts in the business environment or pro-labor activities around ROWTT enactment, we study whether state corporate tax changes co-vary with the enactment of ROWTT policies. State corporate tax rates change with reasonably high degree of frequency, providing an index of the state's business environment year over year. We take advantage of a dataset constructed by Slattery and Zidar (2020), and replicate our event study analysis with state corporate tax rates as the dependent variable. We find that corporate tax rates do not change around ROWTT enactment. Coefficients are economically small, and the confidence interval always includes zero. In Appendix Section A.10 we present the details of this analysis, as well as describe how a wide range of state-level variables correlate with the timing of ROWTT.

\section{III.B. Examining other Transparency Policies through a Bargaining Framework}

Our model predicts similar equilibrium labor market outcomes across a wide range of pay transparency policies, as we discuss in Appendix Section D.1. This allows us to extend our

\footnotetext{
${ }^{33} \mathrm{VT}$ enacts a new law about working mothers in the workplace, and new guidelines supporting flexible working arrangements. MN sets aside money for grants to create programs to hire women in different workplaces. NH creates additional anti-retaliation laws. DE creates new provisions and protections regarding reproductive health. Salary history bans, salary range posting mandates and wage gap disclosure policies are not coupled with ROWTT laws nor are they enacted within several years of any ROWTT law that we study in the window 2004 to 2016.
} 
empirical analysis to include recent pay transparency laws evaluated in other contexts, including laws requiring employers to share information about wage gaps between men and women, as in Austria, the United Kingdom, and Denmark.

We compile results from studies that evaluate these policies to test the equilibrium effects. We refer to this empirical exercise as a meta-analysis, because we examine average wage declines across settings and combine the data from these studies in a mixed-effects meta-regression to test our comparative static prediction that wages decline less when unionization rates are higher.

\section{III.B.1. Criteria for selecting pay transparency studies}

We aim to include the universe of pay transparency studies, subject to certain criteria: first, the study must evaluate the effect of a pay transparency policy in a real-world labor market. Second, the study must evaluate the effect of pay transparency on the wages of all employees in that labor market. Third, the study must refer to the policy evaluated as "pay transparency" or a related term. We include details on our study selection process and each selected study in Appendix Section B.

While we take steps to identify the universe of studies that meet these criteria, one concern with meta-analyses is that publication bias results in studies skewed toward finding a significant effect (Andrews and Kasy, 2019). In our case, this is a relatively minor concern. Overall wage levels are only a secondary outcome in all of these studies; one study (Mas, 2017) primarily focuses on wage compression between high- and low-paid workers, and the remainder focus first and foremost on the gender wage gap, consistent with the stated goal of pay transparency policies to close the wage gap between men and women and other minorities.

\section{III.B.2. Overview of studies \&f results extraction}

Our search results in eight independently-conducted papers. Seven of these papers each include one study (Bennedsen et al., 2019; Blundell, 2021; Böheim and Gust, 2021; Duchini et al., 2020; Gulyas et al., 2020; Mas, 2017; Obloj and Zenger, 2020), while Baker et al. (2021) contains two relevant studies, one based on unionized workers and one for non-unionized workers. In total, these papers evaluate six distinct pay transparency mandates spanning five countries. In four of these studies, policies mandate disclosure of individual employee salaries, and in the remaining five, wage gaps between men and women. Appendix Table A.4 provides details about each of the studies.

We extract information about overall wage effects and labor market unionization from each study. We select the author's preferred specification when clear, as is the case for six of the nine studies. When not specified, we select the specification closest to our theoretical framework, i.e. examining wage spillovers within position. For three of the nine studies, the authors do not report a single post-treatment effect. To minimize assumptions about the covariance between estimates, we do not aggregate over annual estimates when authors do not report a single post-treatment 
effect; rather, we choose the final period in the window reported.

All but three studies specifically report the effect of transparency policies on men's wages, and then provide the differential effect of the policy on women's wages. We impute the overall wage effect of transparency by weighing the changes in men's and women's wages by the share of men in the industry, and the pre-transparency ratio of female to male wages.

\section{III.B.3. Results}

In Figure VI, we graphically present the relationship between the share of the workforce covered by a collective bargaining agreement in each study (x-axis), and the estimated effect of the pay transparency mandate on log wages (y-axis). For each study we include two points. The first is an effect size directly reported in the paper and refers to the effect of pay transparency on men's wages. For these point estimates we also plot the reported $95 \%$ confidence interval. We include a second point, lighter in color, to indicate our imputed estimate of transparency's effect on the overall population.

The results of these studies match our theoretical predictions. Observations generally fall below the x-axis, indicating a negative impact of pay transparency on wages (Theorem 2), and follow an upward-sloping line (Corollary 1), indicating that the effect on wages is smaller in magnitude as a higher share of the workforce has wages set by a collective bargaining agreement. The resulting slope on the effect of transparency on men's wages is 0.018 ( $p$-value $=0.008)$, implying that a 10 pp reduction in the share of workforce under a collective bargaining agreement is associated with a 0.18 pp larger decrease in men's wages following a transparency intervention. Studies with nearly full coverage by a collective bargaining agreement see no statistically significant change in wages following the transparency intervention. Our imputed point estimates for all workers (the lighter point) reveal a similar pattern.

Finally, these prior studies provide empirical tests of our Theorem 4 and Corollary 2, stating that higher transparency leads to more equal wages within firm and thus, more equal wages between men and women. Each one of these studies includes panel observations at the level of the firm, allowing the authors to include firm fixed effects and track wages over time. Six studies find that wages between men and women converge, and the remaining three find no statistically significant change. ${ }^{34}$ We capture this pattern in Figure VI. The darker point estimates, reflecting men's wages only, generally fall below the lighter point estimates for the full population, showing wage declines are generally largest for male workers, whose wages have been shown to start out higher than women's.

\section{CONCLUSION}

Pay transparency has been in the political and popular spotlights as a way to combat pay discrimination by improving workers' ability to renegotiate low pay. We present a model of bargain-

\footnotetext{
${ }^{34}$ Details provided in Appendix Section B.
} 
ing, under incomplete information, that corroborates the intuition that transparency leads to more equal pay between co-workers. However, we also find an unintended, and countervailing equilibrium effect of increasing pay transparency: workers' de facto bargaining power decreases as employers credibly refuse to pay high wages in order to avoid costly renegotiations with other workers.

Our model predicts that increasing transparency leads to lower wages. Wage declines in transparency can result from both changes to who is hired and direct changes to wages. In an empirical examination of the enactment of 13 U.S. state-level pay transparency laws between 2004 and 2016, we find that relative wages fall $2 \%$ in states that enact transparency reforms, predominantly due to direct wage adjustments. As predicted in our model, downward pressure on wages is especially pronounced in markets with high individual worker bargaining power, where workers would have otherwise been able to make high wage demands.

Our framework helps explain the wide array of results from prior evaluations of pay transparency policies. A meta-analysis of these studies reveals that wages typically decline following transparency mandates, and by varying degrees. In line with our model predictions, wages decline sharply where workers have high individual bargaining power. These studies also confirm our prediction that pay transparency compresses wages among comparable workers in the same firm. ${ }^{35}$

Our model sheds light on why few firms adopt pay transparency in the absence of a government mandate. Firms face commitment issues in implementing pay transparency policies. After hiring a worker and setting initial wages, a firm finds it profitable to renege on promises of high pay transparency in order to minimize costly renegotiations. Empirically, this bears out: previous studies document that the majority of U.S. firms adopt limited levels of pay transparency (Hegewisch et al., 2011; McCarthy, 2018; Sun et al., 2021). Other barriers may also lead to low levels of transparency despite (or because of) its impact on wages, such as agency issues wherein a manager personally stands to lose from adopting transparency. ${ }^{36}$

The central message of our paper is that the equilibrium effects of pay transparency may differ from its intended or direct effects. Without an equilibrium response in a bargaining framework, we would expect wages to rise after transparency is introduced, as transparency's direct effect of revealing pay disparities allows low-wage workers to negotiate higher pay. There are other equilibrium channels to consider which may also impact wage setting practices in the presence of pay transparency. First, high transparency could lead to public scrutiny, and demand for accountability (Mas, 2017). We would expect this channel to play a large role in public-sector jobs where wages are supported by tax dollars, and where wages are highly visible to the public. Second, transparency could lead workers to experience low morale, and reduce effort or quit their jobs upon learning peers make more money (Akerlof and Yellen, 1990; Bracha et al., 2015; Breza et al., 2018;

\footnotetext{
${ }^{35}$ In so doing, transparency may contribute to the emergence of stable firm wage effects, as studied in the literature on firm-level drivers of wage inequality and reviewed by Card et al. (2018).

${ }^{36}$ In Example 1 and Appendix Section D.4, we additionally show that high value "superstar" firms may not earn higher profits from additional pay transparency.
} 
Card et al., 2012; Cohn et al., 2014; Cullen and Perez-Truglia, 2019; Dube et al., 2019; Perez-Truglia, 2020). In the presence of morale concerns, we would expect an employer to equalize wages only if the productivity consequences from transparency were larger than the additional wage bill incurred, otherwise the employer would rationally allow pay differences to continue (Eliaz and Spiegler, 2013). In follow-up work, we discuss how bargaining forces may subsume morale concerns, leading wages to be equalized even when productivity consequences are small in comparison to the wage gap (Cullen and Pakzad-Hurson, 2022). Continued study of transparency mandates, as policies evolve and spread to new labor markets, will be important to fully elucidate the roles of each mechanism.

\section{REFERENCES}

George A. Akerlof and Janet L. Yellen. The Fair Wage-Effort Hypothesis and Unemployment. The Quarterly Journal of Economics, 105(2), 1990.

Isaiah Andrews and Maximilian Kasy. Identification of and correction for publication bias. American Economic Review, 109(8):2766-94, August 2019.

Joshua Angrist and Victor Lavy. The effects of high stakes high school achievement awards: evidence from a randomized trial. The American Economic Review, 99(4):1384-1414, 2009. ISSN 0002-8282.

Michael Baker, Yosh Halberstam, Kory Kroft, Alexandre Mas, and Derek Messacar. Pay Transparency and the Gender Gap. American Economic Journal: Applied Economics, Forthcoming, 2021.

Erling Barth, Alex Bryson, James C. Davis, and Richard Freeman. It's Where You Work: Increases in the Dispersion of Earnings across Establishments and Individuals in the United States. Journal of Labor Economics, 34(2):S67-S97, 2013.

Morten Bennedsen, Elena Simintzi, Margarita Tsoutsoura, and Daniel Wolfenzon. Do Firms Respond to Gender Pay Gap Transparency? The Journal of Finance, 2019.

Dirk Bergemann and Johannes Hörner. Should First-Price Auctions Be Transparent? American Economic Journal: Microeconomics, 10(3):177-218, 2018.

Truman Bewley. Why Wages Don't Fall During a Recession. Cambridge MA: Harvard University Press, 1999.

Barbara Biasi and Heather Sarsons. Information, Confidence, and the Gender Gap in Bargaining. AEA Papers and Proceedings, 111:174-178, 2021.

Francis Bloch and Harl Ryder. Two-Sided Search, Marriages, and Matchmakers. International Economic Review, 41(1):93-115, 2000.

Jack Blundell. Wage responses to gender pay gap reporting requirements. Centre for Economic Performance Discussion Paper 1750, 2021.

René Böheim and Sarah Gust. The Austrian Pay Transparency Law and the Gender Wage Gap. IZA Discussion Paper 14206, 2021.

Gabriele Borg, Diego Gentile Passaro, and Santiago Hermo. Minimum Wage as a Place-Based Policy: Evidence from US Housing Rental Markets. Mimeo, 2022.

Anat Bracha, Uri Gneezy, and George Loewenstein. Relative pay and labor supply. Journal of Labor Economics, 33(2):297-315, 2015.

Giulia Brancaccio, Dan Li, and Norman Schürhoff. Learning by Trading: The Case of the U.S. Market for Municipal Bonds. Mimeo, 2020.

Hanna Brenzel, Hermann Gartner, and Claus Schnabel. Wage bargaining or wage posting? evidence from the employers' side. Labour Economics, 29:41-48, 2014.

Emily Breza, Supreet Kaur, and Yogita Shamdasani. The Morale Effects of Pay Inequality. Quarterly Journal of Economics, 133(2):611-663, 2018. 
Kenneth Burdett and Melvyn G. Coles. Long-Term Partnership Formation: Marriage and Employment. The Economic Journal, 109(456):F307-F334, 1999.

Ian Burn and Kyle Kettler. The more you know, the better you're paid? Evidence from pay secrecy bans for managers. Labour Economics, 59:92-109, 2019.

David A. Butz. Durable-Good Monopoly and Best-Price Provisions. American Economic Review, 80(5):1062-1076, 1990.

Sydnee Caldwell and Oren Danieli. Outside Options in the Labor Market. Mimeo, 2021.

David Card, Alexandre Mas, Enrico Moretti, and Emmanuel Saez. Inequality at Work: The Effect of Peer Salaries on Job Satisfaction. American Economic Review, 102(6):2981-3003, 2012.

David Card, Ana Rute Cardoso, Joerg Heining, and Patrick Kline. Firms and Labor Market Inequality: Evidence and Some Theory. Journal of Labor Economics, 36(S1):S13-S70, 2018.

Hector Chade. Matching with Noise and the Acceptance Curse. Journal of Economic Theory, 129(1):81-113, 2006.

Kalyan Chatterjee and William Samuelson. Bargaining under Incomplete Information. Operations Research, 31 (5):835-851, 1983.

Alain Cohn, Ernst Fehr, Benedikt Herrmann, and Frédéric Schneider. Social Comparison and Effort Provision: Evidence from a Field Experiment. Journal of the European Economic Association, 12:877-898, 2014.

Thomas E. Cooper and Timothy L. Fries. The most-favored-nation pricing policy and negotiated prices. International Journal of Industrial Organization, 9:209-223, 1991.

Zoë Cullen and Bobak Pakzad-Hurson. Microfoundations of Pay Transparency: Morale and Bargaining. Mimeo, 2022.

Zoë Cullen and Ricardo Perez-Truglia. How Much Does Your Boss Make? The Effects of Salary Comparisons. NBER Working Paper No. 24841, 2019.

Sabrina L. Di Addario, Patrick M. Kline, Raffaele Saggio, and Mikkel Sølvsten. It Ain't Where You're From, It's Where You're At: Hiring Origins, Firm Heterogeneity, and Wages. NBER Working Paper 28917, 2022.

Stephen G Donald and Kevin Lang. Inference with Difference-in-Differences and Other Panel Data. The Review of Economics and Statistics, 89(2):221-233, 052007.

John J. Donohue III and James Heckman. Continuous versus episodic change: the impact of civil rights policy on the economic status of blacks. Journal of Economic Literature, 29:1603-1643, 1991.

Arindrajit Dube, Laura Giuliano, and Jonathan Leonard. Fairness and Frictions: The Impact of Unequal Raises on Quit Behavior. American Economic Review, 109(2):620-663, 2019.

Emma Duchini, Stefania Simion, and Arthur Turrell. Pay Transparency and Cracks in the Glass Ceiling. Mimeo, May 2020.

Alex Edmans, Xavier Gabaix, Tomasz Sadzik, and Yuliy Sannikov. Dynamic CEO Compensation. Journal of Finance, 67(5):1603-1647, 2012.

Kfir Eliaz and Ran Spiegler. Reference Dependence and Labor-Market Fluctuations. NBER Macroeconomics Annual, 28:159-200, 2013.

Tore Ellingsen and Åsa Rosén. Fixed or Flexible? Wage-Setting in Search Equilibrium. Economica, 70(278): 233-250, 2003.

Federal Register, September 2015. URL https://www.govinfo.gov/content/pkg/FR-2015-09-11/pdf/ 2015-22547.pdf.

Sergio Firpo, Nicole M. Fortin, and Thomas Lemieux. Unconditional quantile regressions. Econometrica, 77(3): 953-973, 2009.

Sarah Flood, Mariam King, Renae Rodgers, Steven Ruggles, and J.Robert Warren. Integrated public use microdata series, current population survey: Version 8.0 [dataset]. Minneapolis, MN: IPUMS, 11, 2020.

Xavier Gabaix. Power Laws in Economics and Finance. Annual Review of Economics, 1(1):255-294, 2009.

Xavier Gabaix. Power Laws in Economics: An Introduction. Journal of Economic Perspectives, 30(1):185-206, 2016. 
Simon Gächter and Christian Thöni. Social comparison and performance: Experimental evidence on the fair wage-effort hypothesis. Journal of Economic Behavior \&3 Organization, 76(3):531-543, 2010.

Danula K. Gamage, Georgios Kavetsos, Sushanta Mallick, and Almudena Sevilla. Pay Transparency Initiative and Gender Pay Gap: Evidence from Research-Intensive Universities in the UK. IZA Discussion Paper 13635, 2020.

Charles E Gibbons, Juan Carlos Suárez Serrato, and Michael B Urbancic. Broken or fixed effects? Journal of Econometric Methods, 8(1), 2019.

Michael Z. Green. How the NLRB's Light Still Shines on Anti-Discrimination Law Fifty Years after Title VII. Nevada Law Journal, 14(3):754-769, 2014.

John Grigsby, Erik Hurst, and Ahu Yildirmaz. Aggregate Nominal Wage Adjustments: New Evidence from Administrative Payroll Data. American Economic Review, 111(2):428-471, Feb 2021.

Wulong Gu and Peter Kuhn. Centralization and Strikes. Labour Economics, 5(3):243-265, 1998.

Andreas Gulyas, Sebastian Seitz, and Sourav Sinha. Does Pay Transparency Affect the Gender Wage Gap? Evidence from Austria. Mimeo, July 2020.

Robert Hall and Alan Krueger. Evidence on the Incidence of Wage Posting, Wage Bargaining, and On-the-Job Search. American Economic Journal: Macroeconomics, 4(4):56-67, 2012.

Benjamin Hansen and Drew McNichols. Information and the Persistence of the Gender Wage Gap; Early Evidence from California's Salary History Ban. NBER Working Paper 27054, 2020.

Ariane Hegewisch, Claudia Williams, and Robert Drago. Pay Secrecy and Wage Discrimination. Institute for Women's Policy Research, 2011.

Johannes Hörner and Nicolas Vieille. Public vs. Private Offers in the Market for Lemons. Econometrica, 77(1): $29-69,2009$.

International Labour Organization. Global wage report 2018/19: What lies behind gender pay gaps. Technical report, 2018.

Kenneth L. Judd. The law of large numbers with a continuum of IID random variables. Journal of Economic Theory, 35(1):19-25, 1985.

Supreet Kaur. Nominal Wage Rigidity in Village Labor Markets. American Economic Review, 109(10):3585-3616, 2019.

Ayça Kaya and Qingmin Liu. Transparency and price formation. Theoretical Economics, 10(2):341-383, 2015.

Marlene Kim. Pay Secrecy and the Gender Wage Gap in the United States. Industrial Relations, 54(4):648-667, 2015.

David M. Kreps and Robert Wilson. Reputation and imperfect information. Journal of Economic Theory, 27 (2):253-279, 1982.

Peter Kuhn and Wulong Gu. A Theory of Holdouts in Wage Bargaining. American Economic Review, 88(3): 428-449, 1998.

Peter Kuhn and Wulong Gu. Learning in Sequential Wage Negotiations: Theory and Evidence. Journal of Labor Economics, 17(1):109-140, 1999.

Bradley Larsen. The Efficiency of Real-World Bargaining: Evidence from Wholesale Used-Auto Auctions. Review of Economic Studies, 88(2):851-882, 2021.

Bradley J. Larsen and Anthony Lee Zhang. A Mechanism Design Approach to Identification and Estimation. NBER Working Paper 24837, 2018.

David S. Lee. Training, Wages, and Sample Selection: Estimating Sharp Bounds on Treatment Effects. Review of Economics Studies, 76(3):1071-1102, 2009.

Wolfgang Leininger, Peter B. Linhart, and Roy Radner. Equilibria of the Sealed-Bid Mechanism for Bargaining with Incomplete Information. Journal of Economic Theory, 48:63-106, 1989.

Simon Loertscher and Ellen V. Muir. Monopoly pricing, optimal randomization and resale. Journal of Political Economy, Forthcoming, 2021a.

Simon Loertscher and Ellen V. Muir. Wage dispersion, minimum wages and involuntary unemployment: A mechanism design perspective. Mimeo, 2021b. 
James G MacKinnon and Matthew D Webb. Wild bootstrap inference for wildly different cluster sizes. Journal of applied econometrics (Chichester, England), 32(2):233-254, 2017. ISSN 0883-7252.

James G MacKinnon and Matthew D Webb. Wild bootstrap randomization inference for few treated clusters. The Econometrics of Complex Survey Data, 39:61-85, 2019. ISSN 0731-9053.

James G. MacKinnon and Matthew D. Webb. Randomization inference for difference-in-differences with few treated clusters. Journal of Econometrics, 218(2):435-450, 2020.

Alexandre Mas. Does Transparency Lead to Pay Compression? Journal of Political Economy, 125(5):1683-1721, August 2017.

Kyle McCarthy. Pay Secrecy? 60 Percent in Tech Told Not to Discuss Compensation. Blind Workplace Insights, Jul 2018. URL https://www.teamblind.com/blog/index.php/2018/07/16/ pay-secrecy-60-of-tech-workers-say-yes/.

Claudio Michelacci and Javier Suarez. Incomplete Wage Posting. Journal of Political Economy, 114(6):1098-1123, 2006.

Paul Milgrom and John Roberts. Predation, reputation and entry deterrence. Journal of Economic Theory, 27 (2):280-312, 1982.

Michael Mussa and Sherwin Rosen. Monopoly and Product Quality. Journal of Economic Theory, 18:301-317, 1978.

Tomasz Obloj and Todd Zenger. The influence of pay transparency on inequity, inequality, and the performance-basis of pay in organizations. Mimeo, 2020.

Kathleen Pender. New law bans California employers from asking applicants their prior salary. SF Gate, 2017. URL https://www.sfgate.com/business/networth/article/ New-law-bans-California-employers-from-asking-12274431.php.

Ricardo Perez-Truglia. The Effects of Income Transparency on Well-Being: Evidence from a Natural Experiment. American Economic Review, 110(4):1019-54, 2020.

Macon Phillips. Now Comes Lilly Ledbetter. 2009. URL https://obamawhitehouse.archives.gov/blog/2009/ 01/25/now-comes-lilly-ledbetter.

Roy Radner and Andrew Schotter. The Sealed-Bid Mechanism: An Experimental Study. Journal of Economic Theory, 48:179-220, 1989.

Phillip Reese. See how far union membership has declined in California. The Sacramento Bee, 2019.

Juliana Feliciano Reyes. Why a Google spreadsheet was the most powerful tool for labor in 2019. The Philadelphia Inquirer, Dec 2019. URL https://fusion.inquirer.com/business/ google-spreadsheet-salary-organizing-baristas-journalists-lawyers-20191231.html.

Fernando Rios-Avila. Recentered influence functions (rifs) in stata: Rif regression and rif decomposition. The Stata Journal, 20(1):51-94, Mar 2020. ISSN 1536-867X. doi: 10/ghqmt6.

Nina Roussille. The central role of the ask gap in gender pay inequality. Mimeo, 2021.

Steven Ruggles, Sarah Flood, Sophia Foster, Ronald Goeken, Jose Pacas, and Matthew Schouweiler, Meganand Sobek. Ipums usa: Version 11.0 [dataset]. Minneapolis, MN: IPUMS, 11, 2021.

Mark A. Satterthwaite and Steven R. Williams. Bilateral Trade with the Sealed Bid k-Double Auction: Existence and Efficiency. Journal of Economic Theory, 48:107-133, 1989.

Peter Schmidt. Study Finds Continued Growth of Unions for Faculty Members and Graduate Students. The Chronicle of Higher Education, 2012.

Guido Schwarzer. meta: An r package for meta-analysis. 7:40-45, Dec 2007.

Fiona Scott Morton. The Strategic Response by Pharmaceutical Firms to the Medicaid Most-Favored-Customer Rules. The RAND Journal of Economics, 28(2):269-290, 1997a.

Fiona Scott Morton. The Interaction between a Most-Favored-Customer Clause and Price Dispersion: An Empirical Examination of the Medicaid Rebate Rules of 1990. Journal of Economics \&3 Management Strategy, 6(1):151-174, 1997b.

Avner Shaked and John Sutton. Relaxing Price Competition Through Product Differentiation. Review of Economic Studies, 49(1):3-13, 1982. 
Leo K. Simon and Maxwell B. Stinchcombe. Extensive Form Games in Continuous Time: Pure Strategies. Econometrica, 57(5):1171-1214, 1989.

Gary R. Siniscalco, Erin M. Connell, and Chad Smith. State Pay Equity Laws: Where a few go, many may follow. Mimeo, 2017.

Cailin Slattery and Owen Zidar. Evaluating state and local business tax incentives. Journal of Economic Perspectives, 34.2(Spring):90-118, 2020.

Anna Stansbury. Do US Firms Have an Incentive to Comply with the FLSA and the NLRA? PIIE Working Paper 21-9, 2021.

Liyang Sun and Sarah Abraham. Estimating dynamic treatment effects in event studies with heterogeneous treatment effects. Journal of Econometrics, 2020.

Shengwei Sun, Jake Rosenfeld, and Patrick Denice. On the Books, Off the Record: Examining the Effectiveness of Pay Secrecy Laws in the U.S. Institute for Women's Policy Research, 2021.

Yeneng Sun. The exact law of large numbers via Fubini extension and characterization of insurable risks. Journal of Economic Theory, 126(1):31-69, 2006.

Albertine Veldman. Pay transparency in the EU: A legal analysis of the situation in the EU Member States, Iceland, Liechtenstein and Norway. Technical report, European Commission, 2017.

Wolfgang Viechtbauer. Conducting meta-analyses in $\mathrm{r}$ with the metafor package. Journal of Statistical Software, 36(11):1-48, Aug 2010.

Jelle Visser. ICTWSS Database, version 6.0. Amsterdam Institute for Advanced Labour Studies (AIAS), University of Amsterdam, 2019.

Steven R. Williams. Efficient Performance in Two Agent Bargaining. Journal of Economic Theory, 41:154-172, 1987.

Okan Yilankaya. A Note on the Seller's Optimal Mechanism in Bilateral Trade with Two-Sided Incomplete Information. Journal of Economic Theory, 87(1):267-271, 1999. 
Figure I: Year Right of Workers to Talk (ROWTT) LaW TAKes Effect

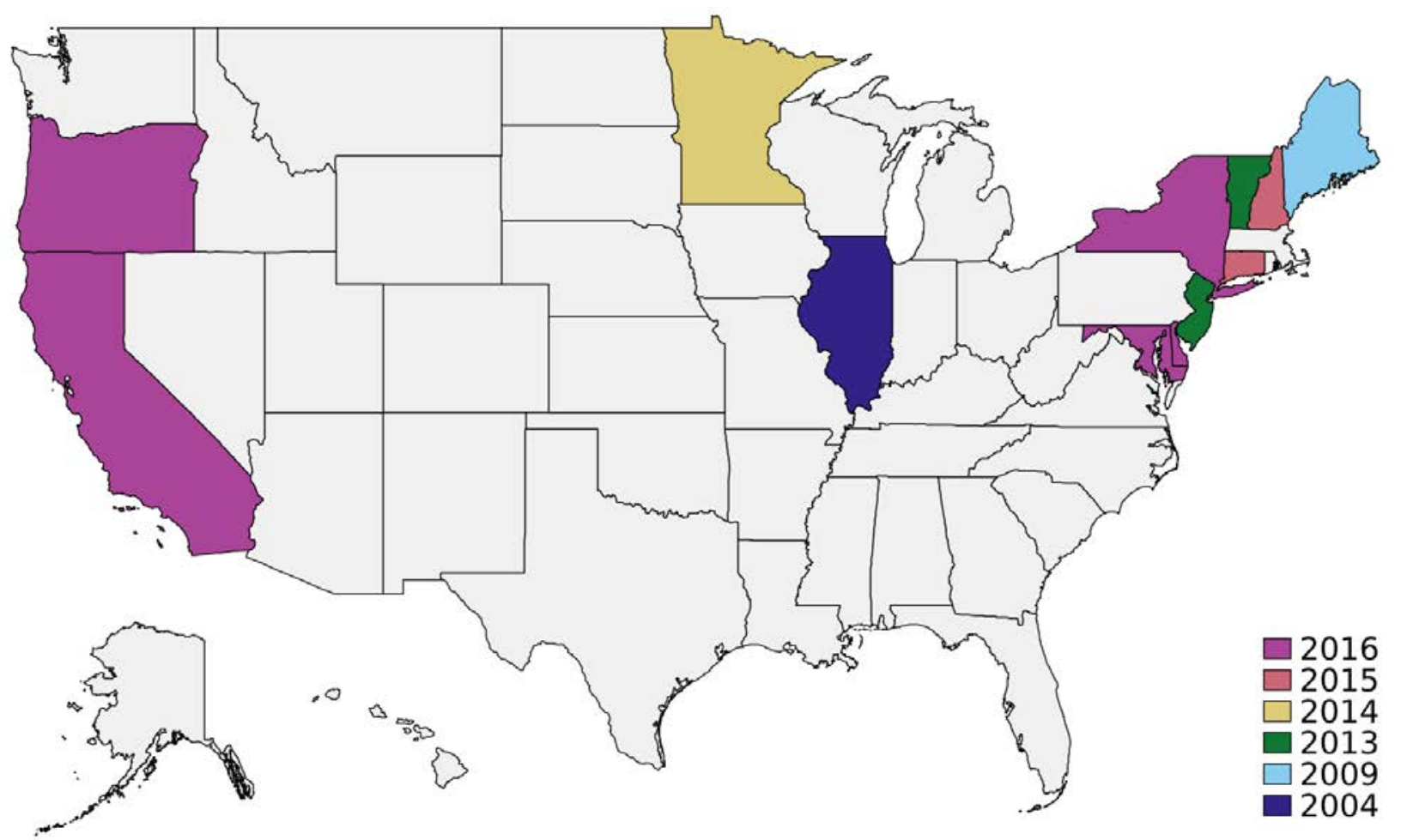

Note: This figure displays the set of states enacting Right of Workers to Talk (ROWTT) policies prior to and including 2016, when a federal ROWTT came into effect. 
Figure II: Percent of Employees Prohibited from Discussing Pay

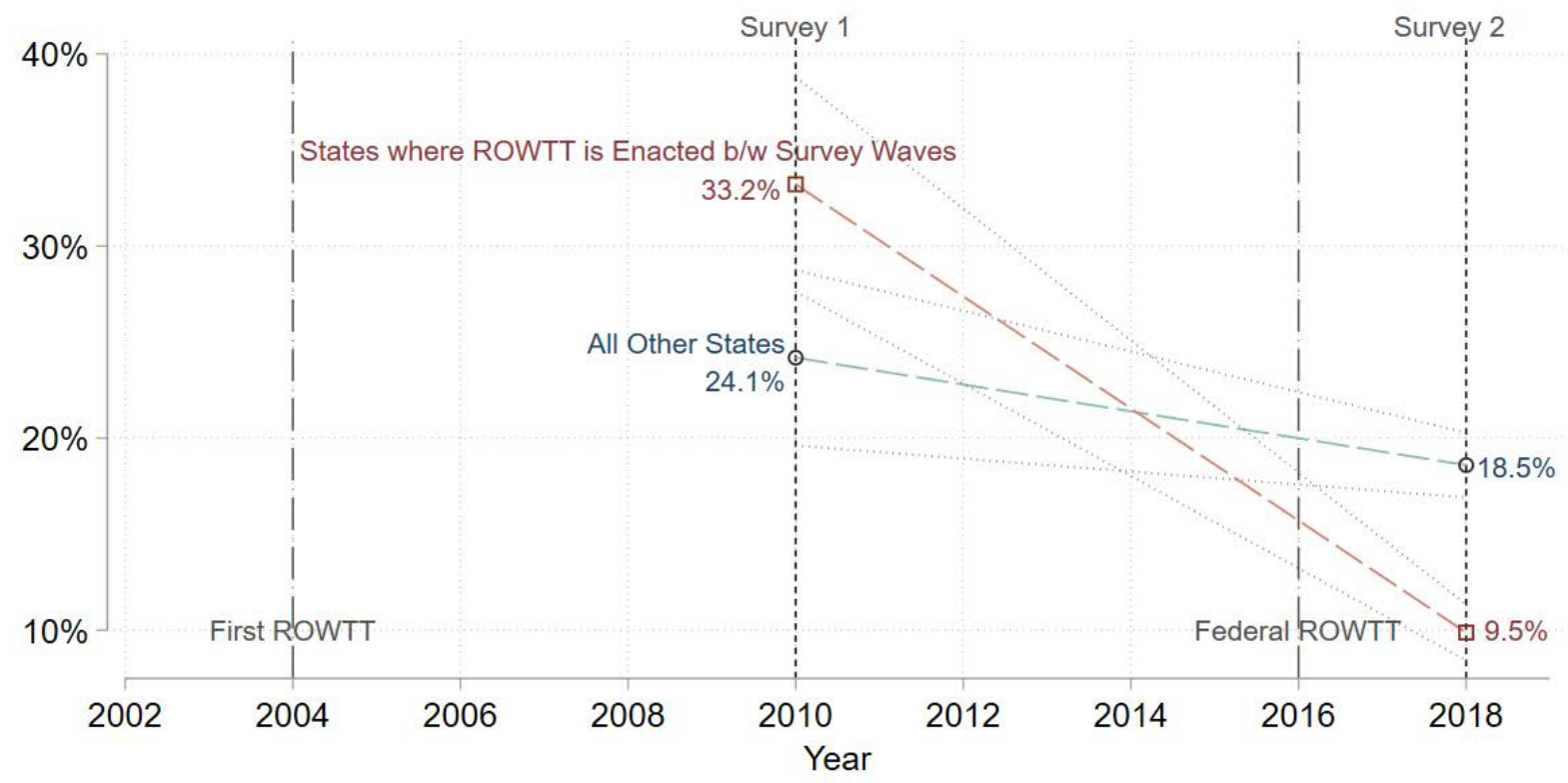

Note: This figure displays the results of a survey tool administered in 2010 and 2017/2018 sampling a crosssection of U.S. employees. We restrict our sample to private sector employees. Survey 1 (2010) N=613 ; Survey $2(2017 / 18) \mathrm{N}=3,785$. Respondents with jobs were asked to indicate whether discussion about pay is formally prohibited, and/or employees caught discussing wage and salary information could be punished. If yes, we codified the answer as "1" and "0" if no. Data from the 2010 sample was collected by the Institute for Women's Policy Research, and results were published in Hegewisch et al. (2011). Data from the 2017/2018 Pay Secrecy Survey was collected by a research team including Dr. Jake Rosenfeld at the Washington University in St. Louis, in partnership with the survey research firm GfK Knowledge Networks (now Ipsos), and results were published in Sun et al. (2021). Responses in the early wave were weighted to match the distribution of responses across states in the later wave. Long-dashed lines offer a linear approximation of the evolution between survey waves. Light grey dotted lines represent $95 \%$ confidence intervals. 
Figure III: Effect of ROWTT Policies on LABor Market Outcomes

PANEL A: WAGE InCOME

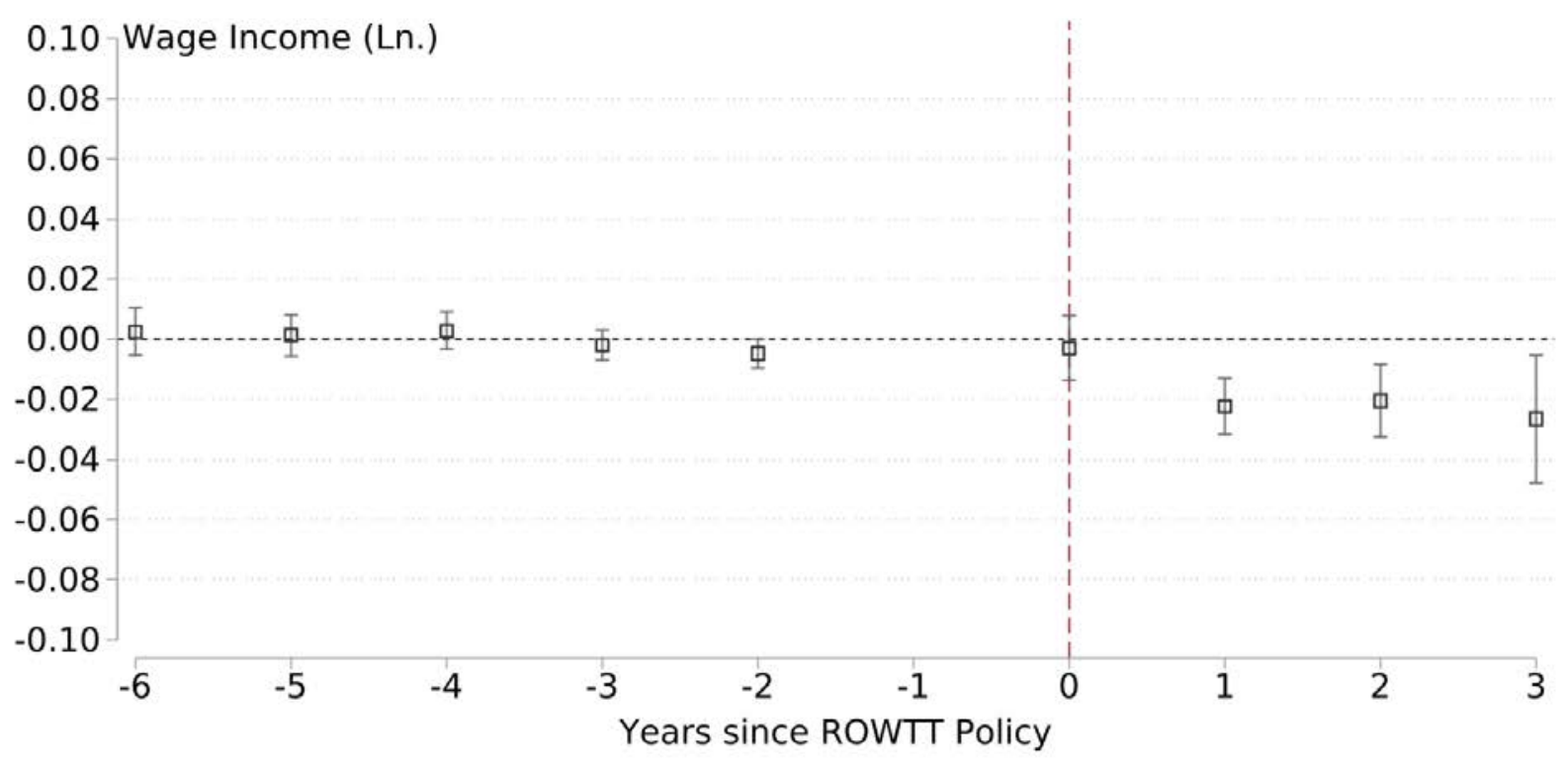

PANel B: EMPloyment

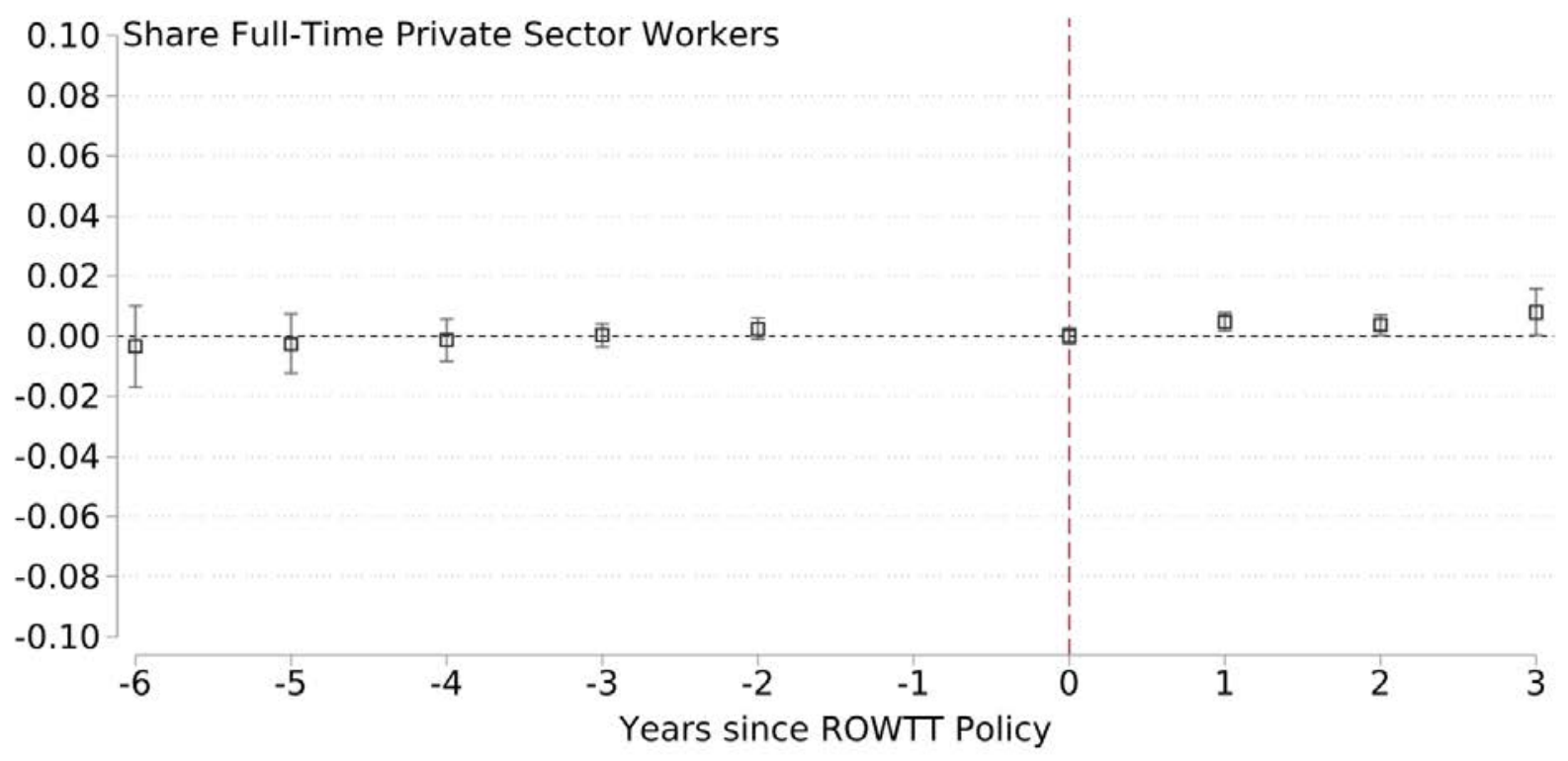

Note: In this figure, we present our baseline multiperiod difference-in-difference estimates. In this baseline specification, we report the results from a balanced composition of states following the enactment of the law. Thus, we estimate the dynamic post period effects for states with events through 2013 separately and report these in periods 0 to +3 . See Equation 7 for more information on this specification. The standard deviation of the state-level mean from 2000 to 2016 is 0.103 for the natural logarithm of wage income and 0.017 for the share of full-time private sector workers. 
Figure IV: Heterogeneous Effects of ROWTt Policies on Wages, By Education Panel A: Wage Income, With vs. Without College Education

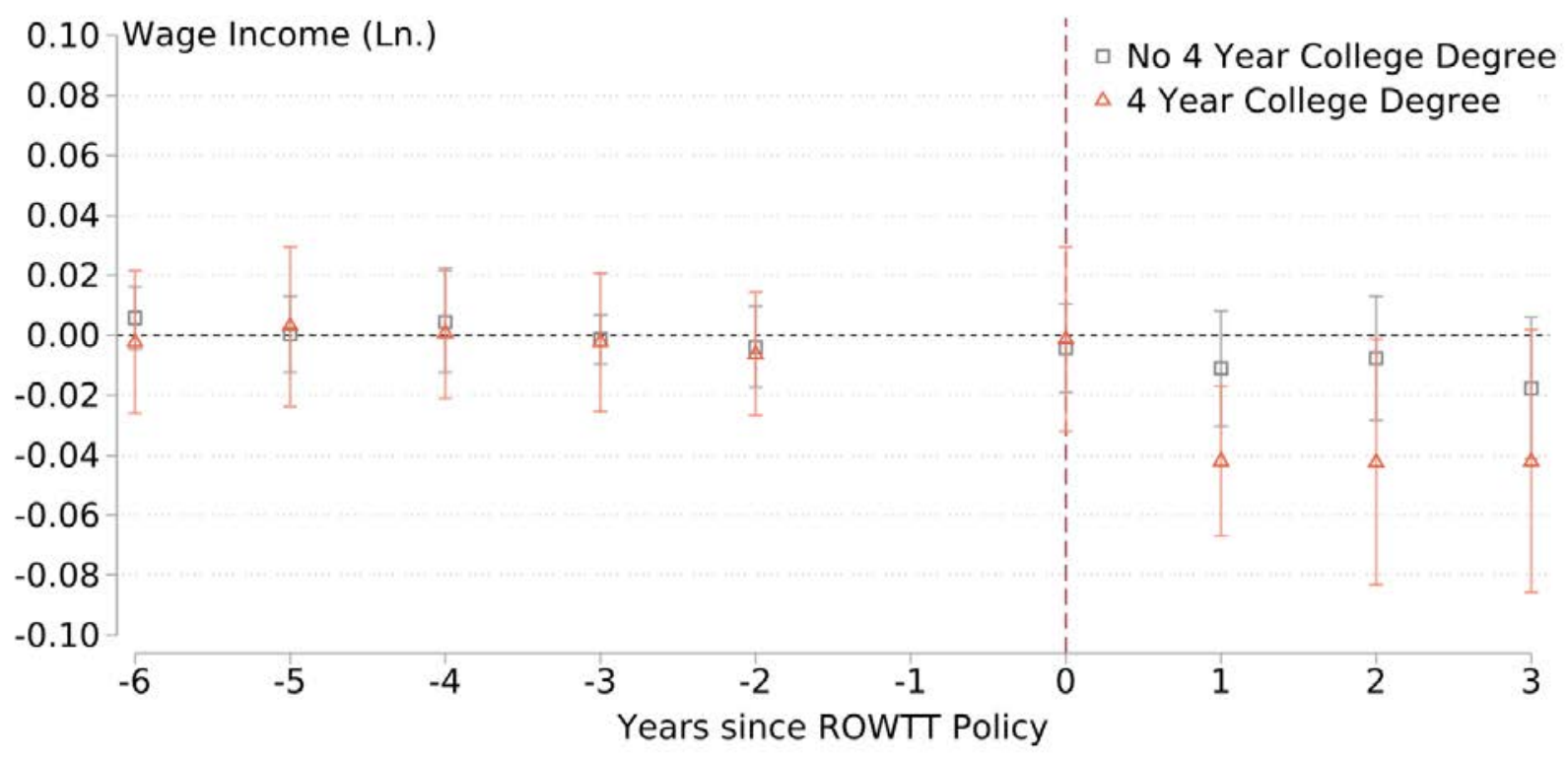

Panel B: Wage Income Difference, With va. Without College Education

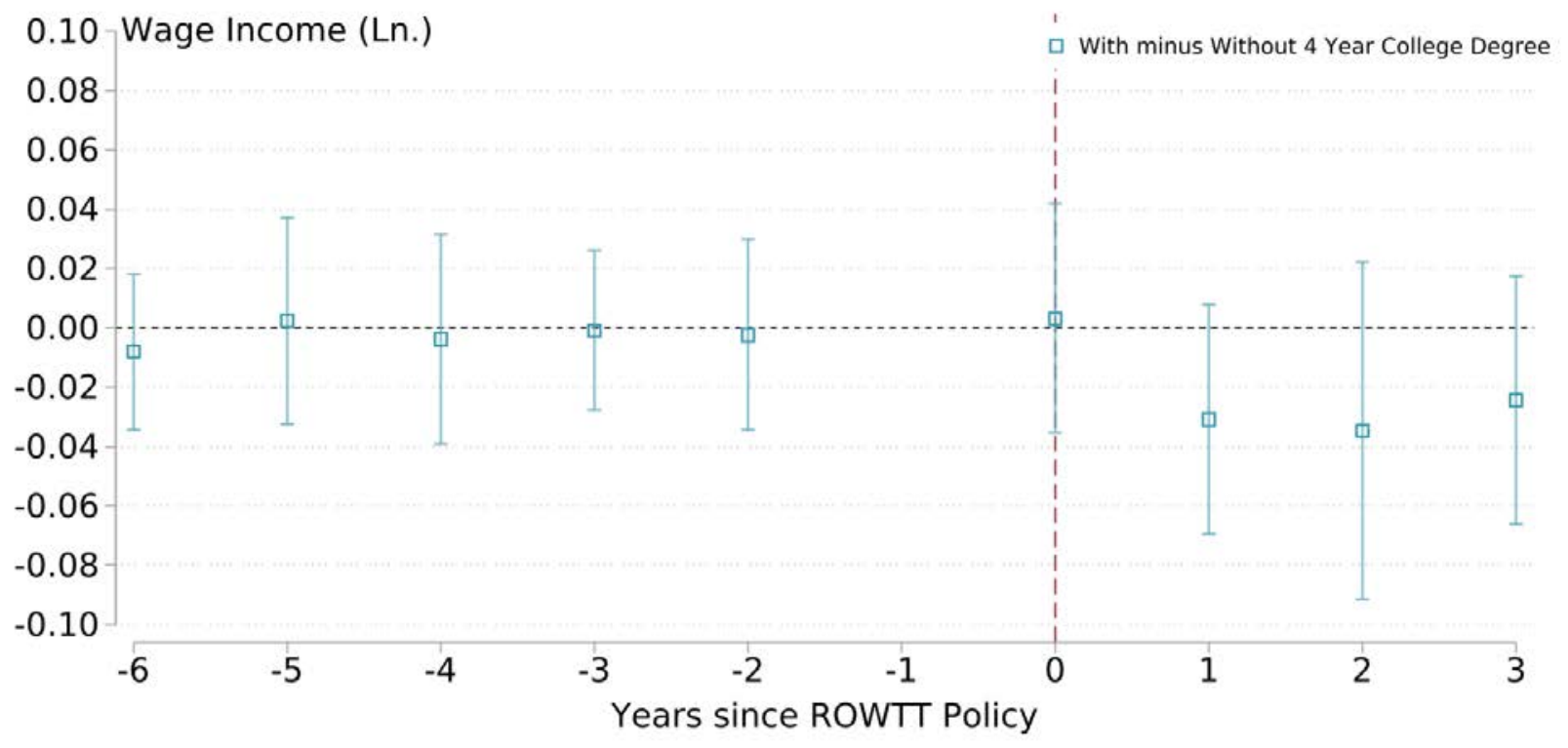

Note: In this figure, we present our baseline multi-period difference-in-difference estimates from a balanced composition of states following the enactment of the law. Thus, we estimate the dynamic post period effects for states with events through 2013 separately and report these in periods 0 to +3 . See Equations 7 and 8 for more information on this specification. The standard deviation of the state-level mean from 2000 to 2016 is 0.103 for the natural logarithm of wage income and 0.017 for the share of full-time private sector workers. We use self-reported education from the ACS to classify workers as having a college degree or not. 
Figure V: Heterogeneous Effects of ROWTt Policies on Wages, By Unionization

Panel A: Wage Income, Below- vs. Above-Median Unionization Rates

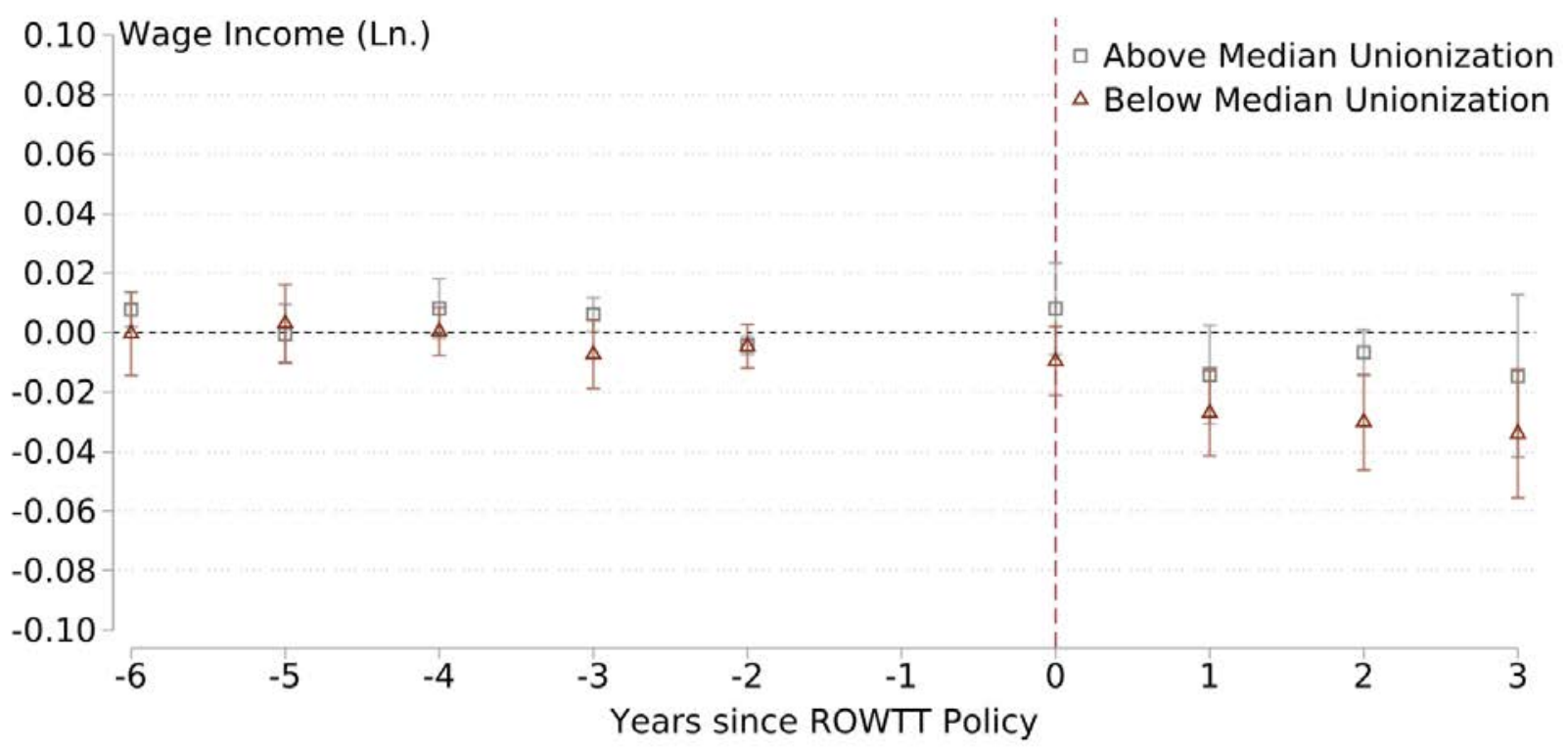

Panel B: Wage Income Difference, Below- vs. Above-Median Unionization Rates

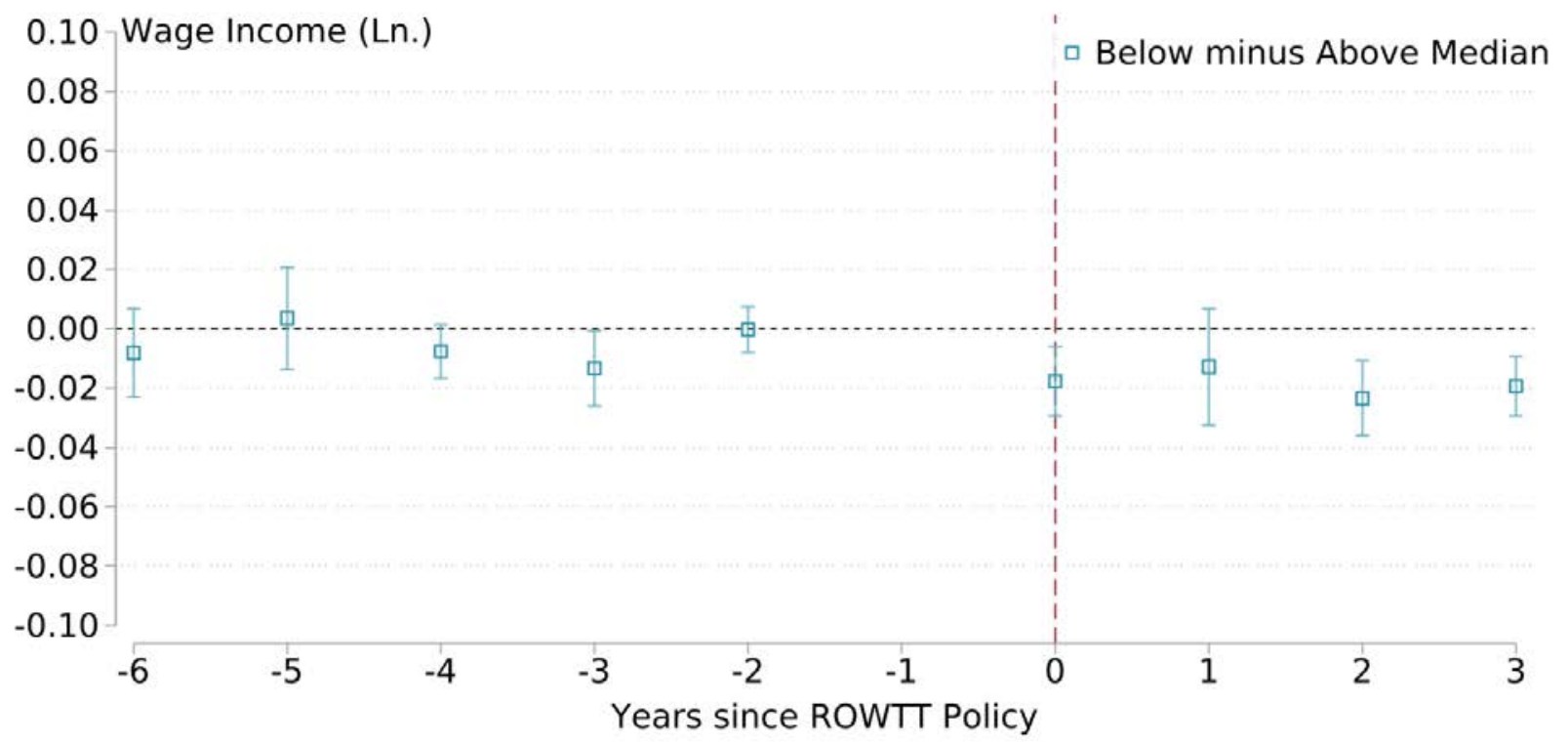

Note: In this figure, we present our baseline multi-period difference-in-difference estimates from a balanced composition of states following the enactment of the law. Thus, we estimate the dynamic post period effects for states with events through 2013 separately and report these in periods 0 to +3 . See Equations 7 and 8 for more information on this specification. The standard deviation of the state-level mean from 2000 to 2016 is 0.103 for the natural logarithm of wage income and 0.017 for the share of full-time private sector workers. We use data from the Current Population Survey to estimate the share of workers covered by a union or collective bargaining agreement at the occupation level each year and split at the median occupation. 
Figure VI: EFFECT

of Transparency on Wages by Individual Bargaining Power, Existing Studies

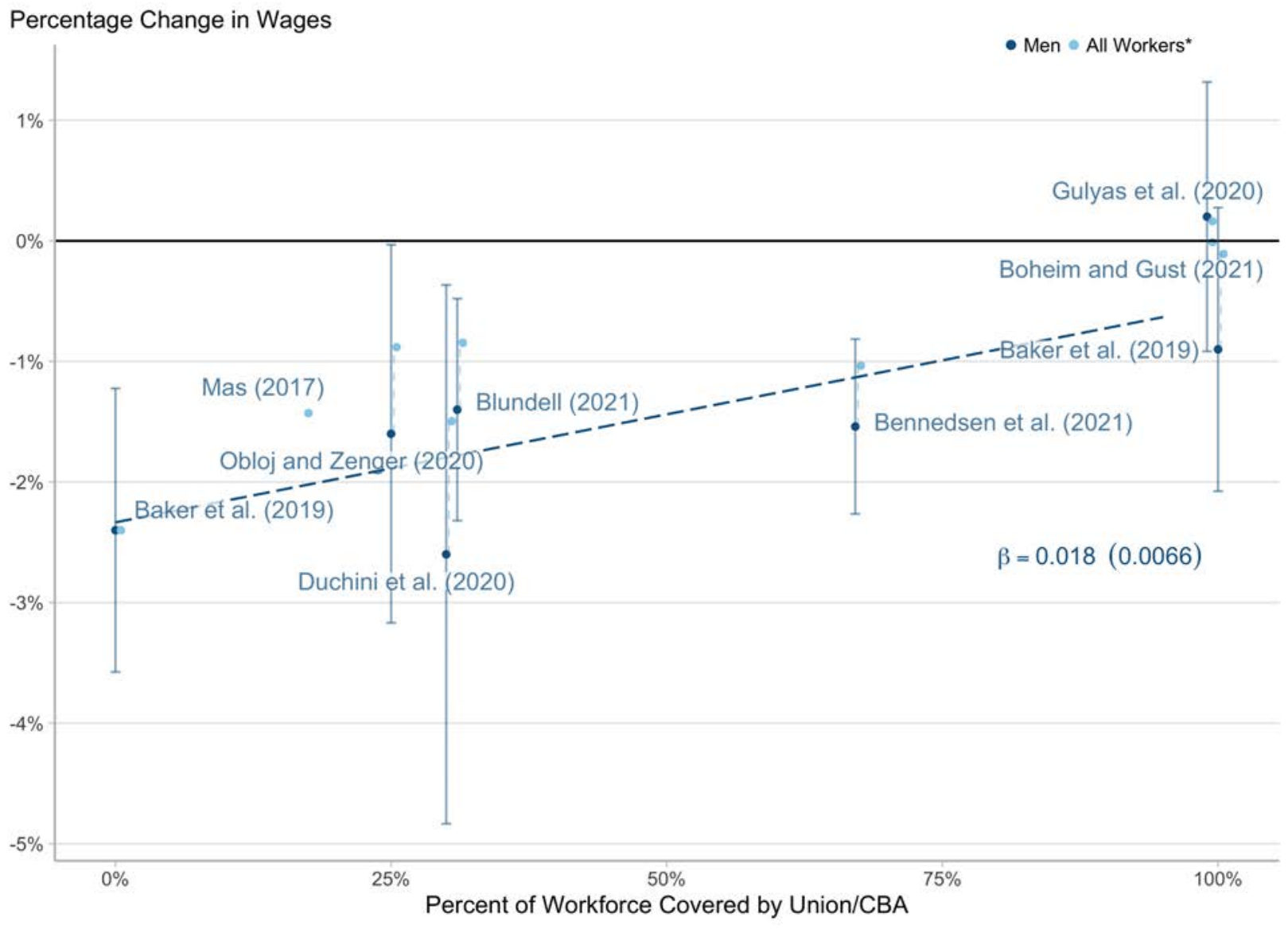

Note: In this figure, we graphically present estimates from the related literature. For the majority of studies, we plot two observations, one for the effect of transparency on the wages of men (dark blue series), and one for the imputed effect of transparency on the wages of all workers (light blue series). Mas (2017) presents the wage effects for "managers" and "non-managers" and we therefore present only an imputed observation for this study. The x-axis represents the share of workers covered by a union/collective bargaining agreement, and the y-axis the percentage change in wages. We report the estimated effect of the unionization rate on the impact of pay transparency recovered from a mixed-effects meta-regression model (Schwarzer, 2007; Viechtbauer, 2010). Since the estimates for all workers are imputed for some studies, we only report the meta-regression results for the male series for which standard errors are known and displayed (we do not include Mas (2017) because wage results for men are not reported. We do not include Böheim and Gust (2021) because the authors' specifications show the change in male wages, not the natural logarithm of change; we display the imputed percent change in male wages by dividing the change in average male wages by the average male wage, as detailed in Table A.4). In Section III.B we describe the criteria for inclusion in our analysis, and provide the details of each study in Table A.4. 
TABle I: Dynamic Effect Estimates: Alternative Specifications

\begin{tabular}{|c|c|c|c|c|c|}
\hline \multirow[b]{3}{*}{ Mean Pre-Treatment Estimate } & Balanced & Unbalanced & Add Reg. $\times$ Yr. FE & Fix Ed. $\times$ Sex Dist. & $\begin{array}{l}\text { Sun-Abraham } \\
\text { IW Estimator }\end{array}$ \\
\hline & \multicolumn{5}{|c|}{ Panel A: Wage Income } \\
\hline & $\begin{array}{l}-0.000 \\
(0.001)\end{array}$ & $\begin{array}{c}0.000 \\
(0.002)\end{array}$ & $\begin{array}{l}-0.002 \\
(0.002)\end{array}$ & $\begin{array}{c}0.001 \\
(0.003)\end{array}$ & $\begin{array}{l}-0.005 \\
(0.001)\end{array}$ \\
\hline \multicolumn{6}{|c|}{ Dynamic Post Treatment Effect Estimates } \\
\hline$t=0$ & $\begin{array}{l}-0.003 \\
(0.005)\end{array}$ & $\begin{array}{l}-0.005 \\
(0.003)\end{array}$ & $\begin{array}{l}-0.003 \\
(0.006)\end{array}$ & $\begin{array}{l}-0.001 \\
(0.004)\end{array}$ & $\begin{array}{l}-0.018 \\
(0.001)\end{array}$ \\
\hline$t=1$ & -0.022 & -0.017 & -0.020 & -0.019 & -0.023 \\
\hline & $(0.004)$ & $(0.006)$ & $(0.007)$ & $(0.004)$ & $(0.002)$ \\
\hline$t=2$ & $\begin{array}{l}-0.021 \\
(0.006)\end{array}$ & -0.015 & -0.020 & -0.019 & -0.022 \\
\hline$t=3$ & $\begin{array}{l}-0.027 \\
(0.010)\end{array}$ & $\begin{array}{l}-0.027 \\
(0.012)\end{array}$ & $\begin{array}{l}-0.024 \\
(0.015)\end{array}$ & $\begin{array}{l}-0.025 \\
(0.009)\end{array}$ & $\begin{array}{l}-0.029 \\
(0.004)\end{array}$ \\
\hline Mean Effect, $t \geq 0$ & $\begin{array}{l}-0.018 \\
(0.005)\end{array}$ & $\begin{array}{l}-0.016 \\
(0.006)\end{array}$ & $\begin{array}{l}-0.017 \\
(0.009)\end{array}$ & $\begin{array}{l}-0.016 \\
(0.004)\end{array}$ & $\begin{array}{l}-0.023 \\
(0.002)\end{array}$ \\
\hline Mean Difference: Post - Pre & $\begin{array}{l}-0.018 \\
(0.005)\end{array}$ & $\begin{array}{l}-0.016 \\
(0.005)\end{array}$ & $\begin{array}{l}-0.014 \\
(0.010)\end{array}$ & $\begin{array}{l}-0.017 \\
(0.004)\end{array}$ & $\begin{array}{l}-0.018 \\
(0.001)\end{array}$ \\
\hline P-Value (CRVE) & 0.002 & 0.011 & 0.170 & 0.002 & $<0.001$ \\
\hline P-Value (WBRI- $\beta$ ) & 0.022 & 0.020 & 0.105 & 0.025 & 0.052 \\
\hline \\
\hline \multicolumn{6}{|l|}{$\begin{array}{l}\text { Microdata : 2,341,955 } \\
\text { Collapsed (State-Year): } 221\end{array}$} \\
\hline Balanced Post-Period & Yes & No & Yes & Yes & Yes \\
\hline Year-by-Region FE & No & No & Yes & No & No \\
\hline Fix Gender-by-Education Composition & No & No & No & Yes & No \\
\hline \multirow{3}{*}{$\begin{array}{l}\text { Mean } \\
\text { (within state SD) }\end{array}$} & 10.77 & 10.77 & 10.77 & 10.77 & 10.77 \\
\hline & $(0.10)$ & $(0.10)$ & $(0.10)$ & $(0.10)$ & $(0.10)$ \\
\hline & \multicolumn{5}{|c|}{ PANel B: EMPLOyMEnT } \\
\hline Mean Pre-Treatment Estimate & $\begin{array}{l}-0.001 \\
(0.003)\end{array}$ & $\begin{array}{l}-0.001 \\
(0.003)\end{array}$ & $\begin{array}{l}-0.000 \\
(0.003)\end{array}$ & $\begin{array}{l}-0.003 \\
(0.003)\end{array}$ & $\begin{array}{c}0.001 \\
(0.001)\end{array}$ \\
\hline \multicolumn{6}{|c|}{ Dynamic Post Treatment Effect Estimates } \\
\hline$t=0$ & 0.000 & -0.000 & 0.000 & -0.001 & 0.000 \\
\hline & $(0.001)$ & $(0.001)$ & $(0.002)$ & $(0.002)$ & $(0.001)$ \\
\hline$t=1$ & 0.005 & 0.002 & 0.002 & 0.004 & 0.003 \\
\hline & $(0.001)$ & $(0.002)$ & $(0.002)$ & $(0.001)$ & $(0.001)$ \\
\hline$t=2$ & 0.004 & 0.005 & 0.004 & 0.004 & 0.002 \\
\hline & $(0.002)$ & $(0.002)$ & $(0.003)$ & $(0.003)$ & $(0.001)$ \\
\hline$t=3$ & $\begin{array}{c}0.008 \\
(0.004)\end{array}$ & $\begin{array}{c}0.007 \\
(0.004)\end{array}$ & $\begin{array}{c}0.006 \\
(0.003)\end{array}$ & $\begin{array}{c}0.007 \\
(0.003)\end{array}$ & $\begin{array}{c}0.007 \\
(0.001)\end{array}$ \\
\hline Mean Effect, $t \geq 0$ & $\begin{array}{c}0.004 \\
(0.001)\end{array}$ & $\begin{array}{c}0.004 \\
(0.001)\end{array}$ & $\begin{array}{c}0.003 \\
(0.001)\end{array}$ & $\begin{array}{c}0.004 \\
(0.001)\end{array}$ & $\begin{array}{c}0.003 \\
(0.001)\end{array}$ \\
\hline Mean Difference: Post - Pre & $\begin{array}{c}0.005 \\
(0.003)\end{array}$ & $\begin{array}{c}0.005 \\
(0.003)\end{array}$ & $\begin{array}{c}0.003 \\
(0.003)\end{array}$ & $\begin{array}{c}0.007 \\
(0.003)\end{array}$ & $\begin{array}{c}0.002 \\
(0.001)\end{array}$ \\
\hline P-Value (CRVE) & 0.108 & 0.133 & 0.331 & 0.064 & 0.224 \\
\hline P-Value (WBRI- $\beta$ ) & 0.168 & 0.148 & 0.210 & 0.111 & 0.726 \\
\hline \multicolumn{6}{|l|}{$\mathrm{N}:$} \\
\hline \multirow{2}{*}{\multicolumn{6}{|c|}{$\begin{array}{l}\text { Microdata : } 5,452,696 \\
\text { Collapsed (State-Year): } 221\end{array}$}} \\
\hline & & & & & \\
\hline Balanced Post-Period & Yes & No & Yes & Yes & Yes \\
\hline Year-by-Region FE & No & No & Yes & No & No \\
\hline Fix Gender-by-Education Composition & No & No & No & Yes & No \\
\hline Mean & 0.43 & 0.43 & 0.43 & 0.43 & 0.43 \\
\hline (within state $\mathrm{SD}$ ) & $(0.02)$ & $(0.02)$ & $(0.02)$ & $(0.02)$ & $(0.02)$ \\
\hline
\end{tabular}

Note: $\mathrm{Obs}=2,341,955$, Clusters $=221$, across all specifications in Panel A. Obs=5,452,696, Clusters $=221$ in Panel B. In Cols. 1-4, we use the standard multiperiod DID estimator to recover the dynamic effect of state-level ROWTT legislation on wage income (Panel A) and on the share of workers in full-time private sector employment (Panel B). For the wage income analysis in Panel A, we explicitly restrict the sample to workers in full-time private sector employment. In Col. 1, we present the baseline model, balancing the set of states identifying the post-treatment dynamic effects by absorbing post-treatment dynamic effect estimates for cohorts with events after 2013. In Col. 2 our estimates includes all cohorts from 2000 to 2016. In Col. 3, we add year-by-region fixed effects to our baseline specification. We pool together the "West North Central" and "East North Central" divisions to form the "Midwest" Census region to ensure that there are no divisions containing only a single treated state. In Col. 4, we reweight our sample by education-by-gender within each state. We take the year before the policy is enacted as the reference year and estimate the educational distribution of each state separately for men and women. Within each state, we then reweight the sample in each year to match the education-by-gender distribution in that state's reference year. In Col. 5, we use the Sun and Abraham (2020) interaction-weighted (IW) estimator to allow for heterogeneous treatment effects across cohorts. The IW estimator requires that the last-treated cohort be used as a control group in the absence of never-treated units. Thus, in this specification, the 2016 cohort does not contribute to dynamic effect estimates. We balance the post-treatment estimate by estimating the full set of cohort-specific dynamic effects, but excluding the 2014 and 2015 cohorts from the post treatment interaction-weighted estimates. In the final two rows of each panel, we report p-values associated with the mean difference between the post-treatment effects and pre-treatment effects calculated first using our cluster-robust variance estimator (CRVE), and second with the wild cluster bootstrap with randomization inference (WBRI- $\beta$ ) described in Appendix Section A.4. 